\title{
RESPONSABILIDADE DE ESTADOS E ORGANIZAÇÕES INTERNACIONAIS EM OPERAÇÕES DE FINANCIAMENTO DE PROJETOS GOVERNAMENTAIS: UM OLHAR CRÍTICO SOBRE AS SALVAGUARDAS SOCIOAMBIENTAIS ${ }^{1}$
}

\section{Fabrício Bertini Pasquot Polido²}

\begin{abstract}
“(...) Developing countries are poor; they make easy marks for anyone selling loans. The imbalance between the sophisticated lender and the less knowledgeable recipient could not be starker. Because they so often result in a struggle for repayment, international loans become the power of global institutions".
\end{abstract}

Joseph STIGLITZ. Making Globalization Work (2006)

RESUMO: Em linha com a agenda contemporânea do direito internacional econômico e sua formulação crítica, o artigo retoma o debate teórico sobre a efetividade dos mecanismos de monitoramento de empréstimos internacionais e salvaguardas socioambientais no contexto das relações entre estados e organizações internacionais. Em destaque, encontram-se concepções sobre governança justa e políticas de controle de operações de financiamento de projetos governamentais, como sugerem os exemplos fornecidos pelo Banco Mundial. Com esse objetivo de análise, o trabalho explora alguns problemas de pesquisa em torno das fragilidades e assimetrias do regime das responsabilidades no direito internacional: o sintomático quadro dos reassentamentos involuntários; a seletividade das ações e atos de violação de obrigações internacionais de direitos humanos e proteção do meio ambiente; e a ofensiva pela interface entre

\footnotetext{
$1 \quad$ O presente artigo inédito constitui versão expandida da conferência intitulada "Responsabilidade de Estados e Organizações Internacionais pela violação de direitos humanos em operações de empréstimos para projetos governamentais", que fez o autor por ocasião do Seminário "Políticas Públicas, Direitos Humanos e Financiamentos Sustentáveis", realizado entre os dias 21 e 22 de maio de 2015, pela Procuradoria Geral da República, $3^{\text {a }}$ Região, e Escola da Defensoria Pública do Estado de São Paulo. Nesse sentido, agradece imensamente a todos que, de modo generoso e aberto, contribuíram para o aprofundamento deste trabalho, em particular Dra. Sandra Akemi S. Kishi (PGR), Dra. Thalita Verônica Gonçalves Silva (DPE-SP), Profa. Dra. Consuelo Yoshida (TRF 3a Região) e o Professor Bruce Rich. As investigações preliminares sobre o tema analisado no estudo resultaram das atividades de pesquisa do Projeto "Estado e Mundialização nas Fronteiras do Trabalho e Tecnologia", do Programa de Pós-Graduação em Direito da UFMG, e da Clínica de Práticas e Pesquisa em Diplomacia Federativa e Cooperação Internacional da UFMG. Pela assistência e coleta de material de pesquisa, o autor agradece à Luiza Couto Chaves Brandão, Humberto Fonseca Brito e Yago Costa, graduandos em Direito pela Faculdade de Direito da UFMG e bolsistas do Conselho Nacional de Desenvolvimento Científico e Tecnológico CNPq e do Programa Jovens Talentos para Ciência -CAPES.

2 Professor Adjunto de Direito Internacional da Faculdade de Direito da Universidade Federal de Minas Gerais - UFMG. Professor do Corpo Permanente e Coordenador do Programa de Pós-Graduação em Direito da UFMG. Doutor em Direito Internacional pela Universidade de São Paulo (2010). Foi Pesquisador-Bolsista do Instituto Max-Planck para Direito Internacional Privado e Comparado, Hamburgo (2012). É membro da Associação Americana de Direito Internacional Privado, da Sociedade de Direito Internacional Econômico, e da International Law Association. E-mail do autor: fpolido@ufmg.br.
}

- Artigo convidado 
obrigações financeiras e direitos humanos. A prática brasileira é ilustrada a partir da perspectiva das operações de endividamento do Estado, em seus entes federativos, e reflexos socioambientais decorrentes de projetos financiados pelo Banco Mundial. Conclui-se pelas recomendações sobre a necessária convergência de competências e responsabilidade compartilhada entre estados e organizações internacionais, com a possível adoção de estudos de impactos em direitos humanos (EIDHs) na formulação e execução dos projetos governamentais financiados.

PALAVRAS-CHAVE: direito internacional econômico; responsabilidade internacional; organizações internacionais; empréstimos internacionais; salvaguardas socioambientais; Banco Mundial; deslocamentos forçados; direitos humanos.

ABSTRACT: In line with the contemporary agenda of international economic law and its critical formulation, this article recalls the theoretical debate on the effectiveness of the monitoring mechanisms for international loans and social-environmental safeguards within the relations between states and international organizations. In spotlight, there are concepts of 'fair governance' and policy review over financing transactions and governmental projects, as suggested by the examples provided by the World Bank. With this goal in mind, the article explores some research issues surrounding the fragilities and asymmetries of the exisiting legal regime of responsibilities in international law: the symptomatic framework of involuntary resettlements; the selectiveness of actions and wrogful acts targeting international obligations on human rights and environmental protection; and the offensive through the interplay between financial obligations and human rights. The Brazilian practice may be briefly outlined from the standpoint of foreign debt related transactions carried out by the State and federative entities, and the relevant social and environmental impacts arising from local projects financed by the World Bank. It concludes with some recommendations upon the necessary convergence of powers and shared responsibilities among states and international organizations, with the possible adoption of human rights impact assessment studies (HRIAs) within the scope of desiging and execution of those projects.

KEYWORD: international economic law; international responsibility; international organizations; international loan agreements; social-environmental safeguards; World Bank; forced displacement; human rights

Introdução: Articulando responsabilidade, governança e financiamentos sustentáveis no Direito Internacional

O surgimento das modernas organizações do sistema econômico internacional reunidas no Banco Mundial e Fundo Monetário Internacional, como resultado da Conferência de Bretton Woods, em 1944, deu início a importante fase de cooperação entre estados, complementada, 
posteriormente, pela emergência das Nações Unidas, estabelecida com uma pretensão- ainda que insipiente - de centralidade sistêmica no Direito Internacional. Todos esses eventos embasam, indubitavelmente, o perfil de aprofundamento da institucionalização do direito internacional da cooperação ao longo do rico, e não menos turbulento, século XX.

O Banco Mundial, como se sabe, foi concebido para fomentar a reconstrução e desenvolvimento das economias europeias destruídas no contexto da Segunda Guerra Mundial, tendo passado por diversos ciclos ou fases de reorientação de suas competências e funções na ordem econômica internacional. De modo genuíno, o papel da Organização tem sido o de estimular soluções para questões de desenvolvimento econômico e auxílio aos países em desenvolvimento, a partir de um eixo monetário e de alocação de recursos em escala global. No final da década de 1960, ele passou a se dedicar, de modo intensivo, ao financiamento para o setor público dos Estados, especialmente no segmento de infraestrutura: ao longo da década subsequente, reorientou suas atividades de modo a vincular empréstimos internacionais a programas de políticas econômicas, característica que até hoje demarca sua atuação ${ }^{3}$. Estabelecendo-se uma análise mais crítica, o Banco não foi capaz de suportar políticas claras e consistentes para dar conta de questões mais sensíveis aos países em desenvolvimento e de menor desenvolvimento relativo, como a erradicação da pobreza em escala global, melhoria de indicadores de proteção de direitos humanos, e que pudessem avançar para além de roteiros, diretrizes e compliances (KAPUR, 2002, p. 54 e ss).

Ao contrário, as diversas crises financeiras sistêmicas desencadeadas nos anos de 1980 e 1990 e as demandas locais dos países que passavam a participar de uma nova ordem econômica internacional pós-descolonização (especialmente Ásia e África) proveram uma corrida por empréstimos internacionais. Foi um período de explosão quantitativa de projetos governamentais diretamente beneficiados por fundos e linhas de crédito especializados, particularmente dependentes das estruturas tradicionais de financiamento por agências multilaterais e regionais (contratos de mútuo, doações, concessão de garantias). Governos de países do então Terceiro Mundo, organizações intergovernamentais e bancos estrangeiros passaram a replicar autênticas relações de desequilíbrio entre tomadores despreparados e

3 É importante ressaltar que o Banco Mundial reúne uma série de instituições: o Banco Internacional de Reconstrução e Desenvolvimento (BIRD, 1945); a Associação Internacional de Desenvolvimento (1960); a Corporação Financeira Internacional (1956); o Organismo Multilateral de Garantia de Investimentos (1988); e o Centro Internacional de Solução de Controvérsias em Matéria de Investimentos (1965). 
mutuantes sofisticados, de um lado, e conflitos e pressões por renegociação e pagamento de dívidas, de outro.

No limite, ainda que se observe o perfil "interestatal" clássico, dos tradicionais cânones do direito internacional público guiando a relação entre sujeitos, a interação entre estados e organizações no tocante aos empréstimos internacionais revela a forma mais crua como países em desenvolvimento são confrontados com o poder das instituições financeiras globais. Esse encontro parece ser inspirado por um embate entre expectativas de captação e concessão de crédito e a mordaça sobre a soberania para adoção de políticas públicas especificamente desenhadas para implementação de certos direitos econômicos, sociais e culturais. Dentro de perspectiva analítica estrutural mais crítica, trata-se de um leque de situações em que as organizações internacionais financeiras delineiam os modelos pelos quais uma espécie de controle externo é estabelecido em relação à discricionariedade dos estados na adoção de políticas públicas em seus sistemas domésticos.

Como se sabe, especificamente no tocante aos empréstimos internacionais $\mathrm{e}$ financiamento de projetos governamentais, diferentes organismos vinculados ao Grupo Banco Mundial são credores nas operações realizadas. Concedem recursos financeiros direcionados para projetos de investimentos e programas de desenvolvimento institucional e políticas públicas. As modalidades são variadas, tais como: (i) empréstimos para desenvolvimento de projetos locais/regionais; (ii) empréstimos setoriais via BIRD, AID; (iii) empréstimos institucionais orientados para reorganização de órgãos governamentais; (iv) empréstimos de ajustes estruturais (objetivando atingir as crises da dívida externa e conversão de recursos econômicos nacionais); e (v) empréstimos a fundo perdido. São essas modalidades que normalmente circundam as tratativas e as escolhas complexas a serem estabelecidas por países tomadores e instituições financeiras quanto à decisão pela captação/concessão de recursos, a reestruturação das dívidas, a anistia e perdão e a declaração de moratória ('default') pela parte devedora ${ }^{4}$.

4 As operações de financiamento negociadas pelo Banco Mundial são estabelecidas individualmente com os Estados, geralmente de cinco anos sem necessidade amortização (período de carência), com prazo de pagamento em 15 e 20 anos, com juros de mercado. Não há possibilidade de reestruturação da dívida ou de cancelamento do empréstimo. A maior crítica formulada é aquela em torno das medidas de correção e de ajustes quanto ao cumprimento das obrigações pelos Estados (“ajustes estruturais"). 
Outros exemplos regionalmente relevantes também podem ser destacados. O Banco Interamericano de Desenvolvimento (BID), criado em 1952, e associado à estrutura da Organização dos Estados Americanos, da qual é Membro o Brasil, também tem estabelecido objetivos prioritários em sua atuação internacional, como a redução da pobreza e da desigualdade social; a promoção da integração regional, principalmente entre América Latina e Caribe; e do desenvolvimento pelo setor privado. Por vários anos, ele dedicou-se à concessão de empréstimos internacionais setoriais, além de subsídios diretos, garantias e acordos de investimentos celebrados com Membros e entes não-governamentais. A origem das fontes é variada, como por receitas originadas nas contribuições de seus Membros, países membros; empréstimos contraídos no mercado financeiro internacional; capital acumulado pelo Banco; e negócios de cofinanciamento.

Mais recentemente, essas organizações foram sendo pressionadas, como será examinado no presente trabalho, a adotar mecanismos de maior representação, transparência e monitoramento nas operações de financiamento de projetos governamentais, sobretudo em países em desenvolvimento e menor desenvolvimento relativo. Neles impactos ou efeitos diretos, decorrentes da execução de acordos internacionais com as organizações, foram sentidos em termos de gestão de orçamento, dívidas internas, constrição ou limitação de políticas públicas (e, por conseguinte, afetando direitos econômicos, sociais e culturais), até danos ao meio ambiente, ao patrimônio histórico e cultural, desemprego e deslocamento forçado das populações ou comunidades locais afetadas.

A principal preocupação suscitada pelo tema reside justamente na medida de interseção entre as salvaguardas socioambientais estabelecidas para essas operações e a observância das obrigações multilaterais de proteção de direitos humanos e do meio ambiente, diretamente endereçadas aos sujeitos de direito internacional. Igualmente, escassas são as formulações sobre base legal e legitimidade para discussão do alcance da responsabilidade de estados e organizações internacionais por danos causados a outros estados, indivíduos e grupos vulneráveis, no curso das operações de financiamento e execução dos projetos governamentais financiados.

Sem pretender esgotar as questões acima descritas, o presente artigo busca examinar os contornos dos mecanismos de monitoramento, empréstimos internacionais, salvaguardas socioambientais, e as interações entre estados e organizações internacionais nesse contexto, 
como discutido na primeira seção. Em destaque, encontram-se as formulações sobre governança justa ('fair governance') e políticas de controle no âmbito das organizações internacionais, como sugere o exemplo do Banco Mundial, e as críticas a elas formuladas. Na segunda seção, são analisados os principais contrapontos entre financiamentos internacionais, direitos humanos e salvaguardas socioambientais, tendo como referência alguns problemas de pesquisa, especificamente quanto ao reclamado envolvimento vis-à-vis o alegado absenteísmo das organizações. Nesse sentido, o artigo enfatiza três frentes distintas: o sintomático quadro dos reassentamentos involuntários; a seletividade das ações e atos de violação de obrigações internacionais; e a ofensiva pela interface entre obrigações financeiras e direitos humanos, especialmente conduzida pelo Conselho de Direitos Humanos das Nações Unidas, em cooperação com o Alto Comissariado para Direitos Humanos. A terceira seção volta-se para a prática brasileira relativa ao financiamento internacional de projetos governamentais, concentrando-se nas operações de endividamento do Estado, em seus entes federativos, e os reflexos socioambientais observados. Por fim, são formuladas algumas recomendações sobre a convergência de competências e a responsabilidade compartilhada entre estados e organizações internacionais no contexto das operações de empréstimos, com a possível adoção de estudos de impactos em direitos humanos (EIDHs) na formulação e execução dos projetos governamentais financiados.

\section{Empréstimos internacionais, mecanismos de monitoramento e salvaguardas socioambientais}

\subsection{Nova governança das organizações internacionais, monitoramento e políticas de controle}

Nas últimas duas décadas, as principais organizações financeiras internacionais atuantes nos domínios da cooperação econômica, tais como Banco Mundial, Fundo Monetário Internacional e Banco Interamericano de Desenvolvimento, têm sido confrontadas com a necessidade de reorientar seus objetivos institucionais e atribuições, além do desenvolvimento de programas sob as lentes de uma "nova governança" (WOODS, 1997, p. 10 e ss; STIGLITZ, 2003, p. 111 e ss; ROCARD, 2014, p. 101 e ss). Expressões abertas - e não menos politicamente atrativas - como democracia, transparência, prestação de contas e responsabilidade - tornaram- 
se elementos obrigatórios da narrativa conceitual de missões e objetivos institucionais das organizações.

O Banco Mundial, por exemplo, passou a discutir possíveis linhas de intersecção entre suas políticas vigentes de concessão de empréstimos a Estados Membros e objetivos sistêmicos internacionais mais amplos de proteção dos direitos humanos e do meio ambiente. Nesse sentido, nas duas últimas décadas, o Banco impulsionou o funcionamento de seu Painel de Inspeção, criado em $1993^{5}$. Em verdade, o movimento sintetizou uma estratégia de aperfeiçoamentos dos órgãos existentes e de adoção de salvaguardas socioambientais no âmbito da instituição. Os organismos vinculados ao Banco também iniciaram a elaboração de novos regulamentos de concessão de financiamento de projetos governamentais, atrelando-os a compromissos de sustentabilidade e direito ao desenvolvimento, além de preocupações de transparência e políticas de combate à pobreza.

Todas essas propostas de reorientação foram estabelecidas apesar de todo descompasso operacional concreto sugerido pela literatura especializada entre esses objetivos e aqueles de ampliação de empréstimos internacionais (ZALCBERG, 2012, p. 75 e ss; e ZHOU, 2012, p. 823 e ss). No mais, metas fixadas pelo Banco Mundial, para alcançar um número mais expressivo de Estados tomadores dos empréstimos ou beneficiários de doações, particularmente no eixo SulSul, seriam igualmente evidências de uma ação mais agressiva quanto à concretização de objetivos institucionais originários da organização. Na década de 1980, em virtude da repercussão concreta da adoção, pelo Banco Mundial, de normas relativas aos reassentamentos involuntários (cf. item 2.1.1. infra) decorrentes de projetos por ele financiados, surgiam preocupações com padrões de proteção de meio ambiente e de grupos vulneráveis.

$\mathrm{Na}$ realidade, como observado criticamente por RICH (2015, p.5), políticas de reassentamento de comunidades locais precediam a regulamentação de avaliação de impactos ambientais e outras questões socioambientais implicadas nos projetos financiados pelo Banco. Em 1982, especificamente, haviam sido adotadas as primeiras diretrizes para proteção de grupos indígenas, seguidas de outras destinadas a abranger questões concernentes ao meio ambiente. Especificamente, em 1984, foi publicada a Declaração sobre o Manual de Operações envolvendo

\footnotetext{
5 Esse aspecto será abordado com maior ênfase no item 2.1 infra. Para um debate sobre a origem do Painel de Inspeção e a inclusão de uma agenda crítica em favor dos direitos humanos e proteção do meio ambiente (cláusulas de salvaguardas) nos projetos e operações do Banco Mundial, e amplamente, nas agências multilaterais de fomento, ver LEVINSON, (1992, p. 39 e ss); BRADLOW, (1993, p. 553 e ss); e SHIHATA, (1992, p. 27 e ss).
} 
aspectos ambientais dos trabalhos do BANCO MUNDIAL (1984). O documento estabelecia normas e procedimentos concernentes a projetos, assistência técnica e outros aspectos do trabalho da Organização, que pudessem gerar preocupações do ponto de vista ambiental. A expressão "ambiental" seria interpretada amplamente, para incluir tanto condições naturais e sociais, como bem-estar das populações afetadas por operações conduzidas pelo Banco (BANCO MUNDIAL, 2014, p. 9).

De fato, parece haver consenso de que o instrumento apenas estabelecia "requisitos gerais e vagos" para a avaliação de impactos ambientais previamente à aprovação de projetos (RICH, 2015, p. 4; e MARSCHINSKI; BEHRLE, 2009, p. 102). Até 1989, o Banco não contava com procedimentos específicos sobre avaliação de impactos ambientais em linha com as boas práticas internacionais sobre a matéria e que formassem parte integrante da análise dos pedidos de financiamentos em projetos.

Na mesma década, o Banco elaborou uma série de normativas de proteção da biodiversidade e habitats naturais; de preservação de bens culturais (patrimônio arqueológico e histórico) e controle de pragas, todas em 1987; e de barragens e reservatórios, em 1989. O gradual desenvolvimento de diretrizes nessa área estaria motivado, em larga medida, pelos crescentes movimentos de protesto e pressão pela sociedade civil organizada em países considerados grandes tomadores de empréstimos da instituição, como Brasil e Índia. Tal situação levaria Estados Unidos e outro países doadores a alterarem suas práticas em relação ao Banco, particularmente pelo apelo público que uma campanha contrária poderia representar, caso fossem priorizadas, por exemplo, metas de empréstimos apenas baseadas em indicadores e monitoramento dos pagamentos (RICH, 2015, p.4).

É bem verdade que o Painel de Inspeção constitui expressão de um fórum de diálogo entre a organização e comunidades locais, além de encontrar-se vinculado ao Conselho Executivo do Banco Mundial. Entre suas atribuições estão o monitoramento e acompanhamento dos projetos financiados, a investigação das alegações de violações aos direitos humanos; e a apuração da responsabilidade do Banco e/ou dos Estados devedores. Se de um lado, o caráter de diálogo intergovernamental é expressado pela criação do Painel, para além de representar a abertura em torno de constante remodelação de normas de salvaguarda (ambiental e de direitos humanos), o órgão carece de poderes de supervisão ou monitoramento subsequente de empréstimos (a exemplo de um controle ex post). Também não existe, ao menos tecnicamente 
considerado no direito internacional, qualquer medida de responsabilização da organização por violação de obrigações internacionais. Como será examinado, o Painel dispõe de atribuições limitadas de investigação relativamente aos Membros tomadores, apesar de ser, genuinamente, um órgão de inspeção ${ }^{6}$.

No caso do Banco Interamericano de Desenvolvimento, o instrumento de monitoramento das operações de financiamento internacional é representado, na atualidade, pelo MICI - Mecanismo Independente de Consulta e Investigação. Ele é vinculado ao cumprimento das políticas operacionais do $\mathrm{BID}$, estabelecendo as regras sobre elaboração, execução e supervisão dos empréstimos concedidos pela organização ${ }^{7}$. Criado em 1994, segundo o mandato da Assembleia de Governadores, foi adotado com a finalidade de "elevar a transparência, responsabilidade institucional e eficácia do Banco" em seus programas e projetos (BID, 2010). Segundo informações oficiais, a função do MICI deve ser "exercida de maneira independente pela Administração, com o objetivo de investigar reclamações de partes afetadas que aleguem que o Banco não aplicou corretamente suas próprias políticas operacionais"(BID, 2010).

É importante destacar que as políticas operacionais gerais e setoriais do BID são aprovadas por sua Diretoria Executiva e incluem salvaguardas socioambientais aplicáveis aos projetos empreendidos pela Organização. Segundo o BID, elas são de "observância obrigatória" para todo o pessoal do Banco e servem de guia para a identificação de impactos ambientais e sociais potenciais causados por projetos por ele financiados. No geral, estabelecem ainda os padrões de informação e consulta às populações das regiões afetadas pelas operações do Banco. Comparativamente ao Painel de Inspeção do Banco Mundial, o MICI também é um órgão de investigação, pois recebe e apura as reclamações apresentadas por indivíduos e organizações em virtude de projetos socioambientalmente sensíveis.

$6 \quad$ Nesse sentido: "While the Inspection Panel represents an important opening for review of safeguard policies, and has taken steps to safeguard its independence, it has no powers of supervision, and relatively limited powers of investigation. Particularly where projects are underway, findings of violations may not result in tangible changes" (ZHOU, 2012, p. 836-837). (Tradução livre: Enquanto o Painel de Inspeção represente uma importante abertura para revisão de normas de salvaguarda, e tenha tomado medidas para assegurar sua independência, não tem poderes de supervisão e relativamente poderes limitados de investigação. Particularmente, nos casos de projetos em andamento, conclusões sobre violações podem não resultar em medidas tangíveis de mudança).

7 As políticas operacionais do Banco são definidas como disposições gerais que regulam as atividades da Instituição, tanto em âmbito administrativo quanto de relação com os agentes financiados. De acordo com sua natureza, essas políticas podem ser gerais, quando tratam das operações comuns do Banco; financeiras, que regulam os financiamentos, suas fontes e condições; setoriais, as quais regulam empréstimos de um setor específico, definindo marcos estratégicos; multissetoriais quando envolvem vários campos econômicos; e documentos que disciplinam a elaboração e aprovação de novas políticas. Informação disponível no website do BID: $<$ http://www.iadb.org/pt/sobre-o-bid/politicas-operacionais-gerais,6236.html $>$. Acesso em 30 de dezembro de 2016. 
Por fim, em relação ao Fundo Monetário Internacional, toda a atuação em relação a estados tem sido escrutinada a partir de mecanismos de avaliação externa a partir das atribuições ao Escritório de Avaliação Independente ${ }^{8}$. Criado em 2001, como um braço do Conselho de Diretores Executivos, o Escritório objetiva estabelecer metodologias de análise sobre as políticas da Organização, produzindo relatórios e estudos ${ }^{9}$.

Seja por meio de órgãos seja pela adoção de mecanismos e procedimentos, as organizações internacionais acima mencionadas sofreram intensas transformações estruturais de modo a se ajustar ao movimento da "boa governança", particularmente com o objetivo de atender a uma agenda de demandas da sociedade civil internacional e de governos de países em desenvolvimento (WOODS, 1997, p. 40). Parece, contudo, que as práticas adotadas não seriam por si só suficientes para blindagem das organizações de eventual imputação de responsabilidade por violação de normas internacionais relativas a domínios conexos às áreas afetadas por políticas setoriais e/ou programas de financiamentos e ajustes estruturais (como em relação ao meio ambiente e direitos humanos de comunidades dos Estados receptores).

\subsection{Salvaguardas socioambientais como parâmetros de controle de legalidade} internacional das operações?

Para qualquer precisa crítica a respeito da forma como agências multilaterais de fomento desempenham suas funções internacionais na regulamentação de financiamentos a projetos governamentais e questões de responsabilidade internacional, é relevante delimitar a noção e o alcance das salvaguardas socioambientais. Enquanto cláusulas em acordos ou previstas em diretrizes e guias de conduta associadas à atuação de organizações internacionais e de Estados no trânsito econômico internacional, elas coexistem com obrigações costumeiras e tratados e convenções no Direito Internacional, em particular em matéria de proteção dos direitos humanos e meio ambiente.

As salvaguardas socioambientais (ESS - "Environmental and Social Standards") do Banco Mundial, por exemplo, tangenciam padrões gerais concernentes a, dentre outros,: (i) condições de trabalho e emprego; (ii) avaliação e gestão de riscos e impactos sociais; (iii) saúde

\footnotetext{
8 Independent Evaluation Office. Informações em: http://www.ieo-imf.org/ieo/pages/IEOHome.aspx.

9 A lista completa dos documentos, desde 2001, encontra-se toda disponível na internet, em: http://www.ieoimf.org/ieo/pages/IssuesPapers.aspx.
} 
e segurança comunitárias; (iv) reassentamento involuntário; (v) direitos de povos indígenas; e (vi) proteção do patrimônio histórico, cultural e urbanístico dos países e comunidades afetadas pelos projetos sob financiamento internacional.

De uma análise preliminar, a adoção de salvaguardas socioambientais representa uma preocupação retórica antiga do Banco Mundial quanto aos efeitos ou desdobramentos de suas operações nos contextos domésticos de Estados beneficiários dos empréstimos (desde uma perspectiva eminentemente nacional até outra regional e comunitária). Como mencionado anteriormente, essa preocupação resulta da pressão internacional, não apenas por nova governança das organizações atuantes no amplo quadro das relações econômicas internacionais, mas também pela observância de normas internacionais de proteção dos direitos humanos e do meio ambiente. Daí porque, como será examinado, a observância ou respeito às normas internacionais de outros regimes - de proteção do meio ambiente e dos direitos humanos simboliza uma tarefa pendente mesmo no contexto de desenvolvimento e de adensamento de juridicidade no Direito Internacional (e não de mera fragmentação).

No caso do BID, como mencionado, o Mecanismo de Independente de Investigação e Consulta Independente encontra-se vinculado às principais normas operacionais pertinentes vigentes da organização ${ }^{10}$, dentre as quais se destacam as seguintes:

i. OP-102: Acesso à informação

ii. OP-703: Meio ambiente e cumprimento de salvaguardas

iii. OP-704: Gestão do risco de desastres naturais

iv. OP-707: Manutenção e conservação de obras físicas e equipamentos

v. OP-708: Serviços públicos domiciliares

vi. OP-710: Reassentamento involuntário (“unvoluntary resettlement”)

vii. OP-761: Igualdade de gênero no desenvolvimento

viii. OP-765: Povos indígenas

As normas sobre meio ambiente, adotadas pelo BID, encontram-se associadas aos objetivos mais amplos de redução da pobreza e de desigualdade social e desenvolvimento sustentável, conforme divulgado pela instituição (BID, 2006). Apesar de datarem do final da década de 1970, foram revistas pela Nova Estratégia de Meio Ambiente, conforme atualização 
levada a cabo em 2003. Originalmente, os mandatos continham dispositivos relativos a: (i) fortalecimento dos marcos jurídicos e normativos relacionados ao meio ambiente; (ii) fortalecimento das instituições ambientais; (iii) melhoria da qualidade ambiental nas operações financiadas pelo BID; (iv) promoção da conservação e do uso eficiente de energia nos projetos do Banco; (v) melhoramento das zonas urbanas; (vi) fomento à gestão sustentável dos recursos naturais, especialmente no que concerne às práticas ambientalmente sustentáveis, gestão de recursos hídricos, aproveitamento florestal, biodiversidade, recursos marinhos e agricultura; (vii) temas de transparência e acesso à informação ambiental, e de consulta com as partes interessadas; (viii) garantias de controle de qualidade e a realização avaliações de impacto ambiental; e (ix) fomento à educação e capacitação em matéria ambiental.

Ainda para o Banco Interamericano do Desenvolvimento, projetos financiados devem contribuir para o desenvolvimento econômico e social dos países solicitantes. Além disso, devem ser coerentes com os princípios da organização e contribuir para sua solidez no mercado internacional. Por fim, o projeto deve apresentar "solidez técnica, econômica e ambiental" bem como adequação jurídica e institucional. Na definição das políticas e diretrizes de salvaguardas ambientais, o BID esclarece que todos os projetos serão submetidos à avaliação prévia (controle ex ante) de seus potenciais impactos ambientais, bem como sociais e culturais negativos. Deverão ser apreciados possíveis efeitos diretos e indiretos, regionais e ainda de natureza cumulativa, a depender do caso. De acordo com o resultado da avaliação preliminar, serão definidas as salvaguardas e os mecanismos de correção apropriados. Nesse sentido, os projetos são classificados em categorias, de acordo com a gravidade dos impactos ambientais e sociais constatados.

Operações inseridas na Categoria "A" são aquelas que representam potenciais graves impactos ambientais e sociais e, por isso, devem ser submetidos a análises específicas que atentem para a complexidade dos riscos e rearranjem todo o projeto. Já os casos incluídos na Categoria "B", embora também representem riscos, são menores e de curto prazo. Eles são encaminhados ao Plano de Gestão Ambiental e Social do Banco, que faz análise de questões específicas do projeto. Por último, na Categoria "C" encontram-se as operações de nenhum ou mínimo risco ambiental e social e, portanto, não demandam outra averiguação. Depois de definidas as salvaguardas, de modo casuístico, elas são incluídas no contrato de financiamento e sua observância é acompanhada pelo BID (BID, 2006, p. 9-10). 
Nos dois casos, do Banco Mundial e do BID, parecem existir pressupostos a serem verificados para que as operações financiadas restem endossadas/aprovadas segundo o escrutínio mínimo baseado na aplicação de salvaguardas socioambientais. Qualquer modalidade de "controle de legalidade internacional" exigiria primeiramente a apreciação de indicadores positivos dos projetos em termos de desenvolvimento econômico e social dos países tomadores, além de um teste necessário para verificar se os benefícios gerados anulam prejuízos e externalidades negativas decorrentes da implementação dos projetos.

Em realidade, os mecanismos existentes e disponíveis nas estruturas das organizações internacionais, como nos casos do Banco Mundial e do BID, não seriam suficientes para minimizar os efeitos concretos de violações a normas internacionais vigentes em matéria de direitos humanos e proteção do meio ambiente. Isso porque o próprio regime normativo de direito internacional não aponta para qualquer enquadramento das condutas dos estados e organizações internacionais nas regras vigentes de responsabilidade internacional em matéria de obrigações de proteção de direitos humanos e meio ambiente no contexto dos financiamento de projetos governamentais ${ }^{11}$. No limite, poder-se-ia sustentar a combinação daqueles mecanismos com instrumentos não-excludentes entre si, como o recurso das partes - indivíduos e organizações da sociedade civil - às comissões e tribunais internacionais de direitos humanos ou mesmo aos órgãos judiciários e administrativos dos Estados por violações a direitos humanos e normas ambientais, em particular pelos interesses públicos ali representados.

\section{Financiamentos internacionais, direitos humanos e salvaguardas socioambientais}

A emergência do debate internacional sobre a necessidade de inclusão de salvaguardas socioambientais em ações de financiamento de projetos governamentais pelo Banco Mundial e outras agências multilaterais é fenômeno recente no desenvolvimento do Direito Internacional

\footnotetext{
11 Parece-nos que o Projeto de Artigos da Comissão de Direito Internacional das Nações Unidas de 2011 sobre Responsabilidade Internacional de Organizações (cf. ILC, Draft Articles on the Responsibility of International Organizations, 2011, disponível em http://legal.un.org/ilc/texts/9_11.shtml) oferece ampla margem de discussão sobre quais condutas poderiam ser genericamente enquadradas como suscetíveis de responsabilização, incluindo aquelas em conexão com a prática de Estados e seus órgãos internos, e violadoras de normas internacionais (incluindo as de 'jus cogens' ou peremptórias). Contudo, a precisa imputação de responsabilidade dependeria de previsão normativa especial, e não simplesmente genérica; qualquer indefinição nesse campo também afetaria a delimitação de qual tribunal seria competente para apreciar as reclamações, além de questões sobre legitimação ativa, a saber, quais sujeitos/atores poderiam acionar o tribunal na hipótese das violações.
} 
Econômico $^{12}$. Pode-se afirmar que, ao lado do movimento desencadeado na década de 1970 sobre a consecução da Nova Ordem Econômica Internacional (NIEO), a adoção de resoluções sobre direito ao desenvolvimento pela Assembleia Geral das Nações Unidas, e do adensamento de juridicidade do sistema multilateral do comércio com a criação da OMC em 1994, é a governança socioambiental do Banco Mundial um dos importantes marcos de transformação do sistema econômico internacional. E ela expõe justamente o protagonismo de Estados Membros, de um lado, e de organizações da sociedade civil, de outro, favoravelmente a uma pressão por intenso monitoramento e controle (BUTAINE, 2015, P. 100-101). Por mais controvertidos que sejam os momentos dessas interações, parece ser intuitivo revisar os fundamentos de política normativa e procedimentos pelas organizações internacionais em contextos de absoluta interdependência econômica dos Estados, de globalização e de redução de assimetrias. Na atualidade, ainda que se fale em "governança", "transparência" e "accountability" das organizações, a retórica emergente tem sido a de construir consensos em torno dos imperativos de monitoramento, controle, participação e incentivos democráticos sobre gestão e o funcionamento das principais instituições internacionais (DAHL, 1999, p. 19 e ss; BARNETT; FINNEMORE, 1999, p. 699; e NYE, 2001, p. 2).

A discussão especializada sobre a interface entre operações de empréstimos e financiamentos internacionais, direitos humanos e meio ambiente é, de longe, a mais consistente com uma preocupação sobre aqueles imperativos. De um lado, resistem os tecnicistas e legalistas quanto à afirmação do direito de os Estados postularem auxílio financeiro aos organismos multilaterais de fomento e bancos de desenvolvimento, em particular pela condição de membros. De outro, militantes, organizações da sociedade civil e academia insistem na obrigação de estados e organizações internacionais (independente da natureza, competências ou especialidades envolvidas) de observância de normas de proteção de direitos humanos e do meio ambiente.

Esse inevitável paradoxo é reflexo da elevada especialização e tecnicidade a que foi lançado o direito internacional no contexto do Pós-Guerra, entre uma dinâmica de cooperação em vários domínios e a necessidade de efetividade, fortalecimento e democratização de suas

12 A esse respeito, cf. LEVINSON (1993, p.40 e ss), sobre a divisão tradicional entre países latinoamericanos, de um lado, e a Europa e Estados Unidos, de outro, sobre a governança das organizações internacionais, em particular, FMI, BIRD e Banco Interamericano de Desenvolvimento no contexto do Pós-Guerra e as transformações econômicas e sociais que acompanharam a América Latina, em especial as ondas de redemocratização após períodos de governos ditatoriais. 
instituições. E nem seria preciso falar em "subsistemas" ou "regimes" para reforçar essa tese (KOSKENNIEMI, 2011, p. 35 e ss). Isso porque o direito internacional não se confina em uma única linguagem. Ele atualmente se encontra em uma constelação de efeitos socialmente relevantes no espaço global, com instrumentos que podem ser moldados e manipulados a partir da atuação política de sujeitos, vertidos em atores estatais e não-estatais (KOSKENNIEMI, 2011, p. 228). Apesar de alguns insistirem na aparente complementaridade entre objetivos ou políticas, a realidade das formas demonstra a existência de autênticos conflitos e casos difíceis no tratamento legal das operações de financiamentos públicos internacionais ${ }^{13}$. Estados e seus governos, diante da crescente pressão e demanda por cumprimento de metas, políticas de assistência, acesso ao crédito e à infraestrutura para serviços de utilidade pública, melhores condições de vida das populações locais e desenvolvimento econômico e social, não visualizam óbices para ações mais agressivas de captação externa de recursos financeiros para projetos locais. Em distintos níveis - do municipal, estadual, cantonal ao federal - governos se lançam em ações de diplomacia federativa econômica para, de modo concorrencial, dar conta das demandas e pressões domésticas de implementação de políticas públicas. Áreas como saúde, transportes, energia, educação, agricultura, abastecimento e saneamento são, com frequência, alvos específicos nesses processos. Nos últimos 20 anos, como explica ZHOU (2012, P. 824-25), o Banco Mundial reforçou a inclusão, em suas políticas, além de objetivos de incentivo ao crescimento econômico dos Membros, a preocupação com os efeitos desencadeados por operações de financiamento de projetos sobre os direitos humanos de populações e comunidades afetadas. Segundo a autora, ainda que várias atividades do Banco não tratem diretamente de direitos humanos, muitos dos projetos financiados pela organização resultam em situações concretas de violação, tal como seriam aquelas oponíveis aos Estados em relação a indivíduos prejudicados. Essas representariam, em larga medida, as principais dificuldades e os desafios para articulação entre políticas de concessão e monitoramento de financiamentos internacionais e a observância de padrões de proteção do meio ambiente e direitos humanos. Os próximos itens examinam algumas das nuances da afirmação de políticas de proteção e promoção dos direitos humanos e meio ambiente, tanto do ponto de vista institucional do Banco Mundial, quanto por

13 Exemplificadamente, CLARK (2002,p.212) analisa algumas modalidades de projetos financiados pelo Banco Mundial, nas áreas de educação, saúde, nutrição, moradia, saneamento, que poderiam colidir com objetivos de proteção de direitos fundamentais e meio ambiente em escala global. Entre os mais problemáticos estão os projetos que implicam o deslocamento forçado de pessoas e suas comunidades, com perdas de empregos, de terra e da capacidade de geração de renda. 
parte das agências de desenvolvimento, organizações internacionais para o desenvolvimento e, inclusive, de organizações financeiras privadas (ZHOU, 2012, p. 825-826).

\subsection{Absenteísmo ou envolvimento das organizações?}

Como mencionado, na discussão corrente sobre "nova governança" das organizações internacionais, são frequentes os apelos para expressões como democracia, transparência, responsabilidade e acesso à justiça glmobal (ROCARD, 2014, p. 110-11). Até em que ponto esse discurso se consolida no direito internacional e nas relações internacionais ainda é incerto determinar. $\mathrm{O}$ fortalecimento dos mecanismos de proteção internacional dos direitos humanos e, em menor medida, daqueles do meio ambiente ${ }^{14}$, entretanto, parecem ter conduzido a maior amadurecimento de argumentos discursivos sobre a relevância do neofederalismo das organizações internacionais ${ }^{15}$. Em suma, ele se refere ao compartilhamento e convergência de competências temáticas no quadro de regulação internacional, dos quais resultaria, por exemplo, uma necessária interface entre a disciplina ou "regime" dos financiamentos e aquelas da proteção dos direitos humanos e meio ambiente, a partir do cumprimento de salvaguardas. E curiosamente, elementos clássicos do Estado ou integrantes da estatalidade (statehood), como soberania, território e população, aparecem confrontados por essa inevitável interação ou vinculação normativa.

A força pragmática da negociação e circulação dos instrumentos de crédito internacional, de acordos de financiamento de projetos e de operações financeiras, demonstra, desde a criação do Banco Mundial e do Fundo Monetário Internacional, na Conferência de Bretton-Woods, no século passado, a difícil tarefa de conciliação de objetivos sistêmicos. Em dada proporção, Estados teriam incentivos, em graus distintos, para deixar de ceder a pressões internas e externas pela observância de proteção de direitos de humanos e padrões ambientais. Isso ocorre, sobretudo, em virtude da realidade de constrição orçamentária e pressões por

14 Considerando-se, aqui, os distintos níveis de proteção e de instituições dedicadas a processar reclamações contra violações por parte de Estados e OIs. No caso específico dos direitos humanos, a presença consolidada de tribunais internacionais e regionais reforça patamares de observância de normas internacionais e de responsabilização por condutas de violação. No caso do meio ambiente, a dispersão normativa e a ausência de um órgão internacional ou tribunal especializado podem ser um dos fatores de maior complicação nesse cenário.

15 Empregamos aqui a expressão "neofederalismo" para designar o movimento de reorientação de estruturas e funções das organizações internacionais em espaços integrados por demandas de regulação sistêmica e setorial, em que compartilhamento e convergência são as principais dinâmicas. 
implementação de políticas públicas domésticas em cenários de crise e contingências financeiras que atingem a balança interna de pagamentos.

Essa crítica poderia ser ainda mais contundente quando se tratar da proteção de minorias em comunidades que são atendidas por projetos locais e regionais financiados com recursos internacionais ou programas de reformas estruturais via BIRD-FMI. Do outro lado da cadeia, organismos multilaterais de fomento também não cederiam a argumentos discursivos legítimos sobre proteção de pessoas e bens, diferentemente do que seria o irremediável instinto de preservação e recuperação de ativos transnacionados/negociados nas operações por eles idealizadas. Reforçariam, em sua existência e atuação internacionais, um compromisso de ampliação de oferta de crédito aos Estados Membros, dentro das racionalidades que lhes são próprias, de incentivo ao desenvolvimento econômico, prosperidade e eficiência. Todas elas são típicas dos anacrônicos, e ainda persistentes, paradigmas do Consenso de Washington ${ }^{16}$.

A questão, portanto, é aquela de saber se é justificado o absenteísmo incondicional e deliberado das organizações internacionais ou se há margem para superação dessa conduta pelo envolvimento das instituições com outras áreas de superior importância em relação aos imperativos do crédito e finanças internacionais. As críticas ainda são muitas; não alijam as próprias organizações internacionais de formas variadas de autocontrole e governança mínima. Um dos bons exemplos é aquele da relação paradoxal entre financiamentos concedidos pelo Banco Mundial para projetos em setores específicos dos países mutuários, tais como nutrição, moradia, saneamento e meio ambiente, de um lado, e as compensações ou ajustes obrigatórios, impostos aos estados receptores, de outro. Os paradoxos podem estar sintetizados em problemas concretos de pesquisa, como aqueles relativos aos deslocamentos forçados de comunidades locais em países tomadores de empréstimos, a seletividade das ações e a ofensiva pela interface dos empréstimos e salvaguardas socioambientais.

\subsubsection{Reassentamentos involuntários ou deslocamentos forçados?}

Em casos específicos, o deslocamento forçado (que o Banco Mundial tem frequentemente denominado "reassentamento involuntário" ('involuntary resettlement'),

16 Seria possível cogitar de tal anacronismo, como alguns sustentam, particularmente pelo fato de tanto FMI como Banco Mundial continuarem a defender um modelo produtivo em crise para países em desenvolvimento. (ROCARD, p.102). 
associado à execução de tais projetos, leva populações locais e comunidades a sofrer consideráveis prejuízos de ordem social e econômica, dentre os quais o desemprego, perda de terra e de capacidade de geração de renda. O meio ambiente local e regional, por sua vez, também pode ser afetado pela execução dos projetos, de tal maneira que a responsabilidade civil ou criminal por atos de violação, normalmente imputada a pessoas físicas e jurídicas, não atingiria os governos e o próprio Banco (enquanto organização internacional). Padrões de vida seriam, portanto, confrontados com níveis nada promissores em termos de respeito aos padrões de proteção do meio ambiente e direitos humanos. Em linha com essa crítica, CLARK (2002, p. 212) observa:

The World Bank's policy on Involuntary Resettlement requires that people displaced by Bank-financed projects share in the benefits from those projects, and that their standard of living be improved, or at least restored. In practice, however, the minimum requirements of the policy have rarely been met. The norm is that people who are involuntarily resettled suffer a decline in their living standards. ${ }^{17}$.

Estudos realizados pelo próprio Banco Mundial, de modo transparente e crítico, demonstram que o reestabelecimento dos padrões de vida dos deslocados tem fracassado e, portanto, projetos financiados pelo Banco Mundial com implicações negativas abririam margem para violação de direitos da comunidade deslocada e de normas de proteção do meio ambiente. Em síntese, esses projetos poderiam levar ao rompimento do tecido social, com consequências econômicas, sociais, culturais, psicológicas e estruturais (CLARK, 2012, p. 212-13).

Essas situações, como também ressalta CLARK (2002, P. 214), são manifestamente contrárias às normas do direito internacional dos direitos humanos e violam especialmente "os direitos a melhores condições de vida, à moradia adequada, à propriedade e ao trabalho". Assim, a probabilidade (ou riscos) de violação de normas do direito interno e internacional em decorrência do deslocamento forçado de pessoas é maximizado pelo fato de que comunidades geralmente são econômica e politicamente marginalizadas pelas próprias instituições domésticas do Estado tomador dos empréstimos.

17 Tradução livre: “A normas do Banco Mundial sobre Reassentamento Involuntário exige que as pessoas deslocadas por projetos financiados pelo Banco compartilhem os benefícios desses projetos, e que o seu nível de vida seja melhorado ou, pelo menos, restaurado. Na prática, porém, os requisitos mínimos das normas raramente foram cumpridos. A regra é a que pessoas involuntariamente reassentadas sofram um declínio em seu padrões de vida". 
Com efeito, o Banco Mundial tem travado um processo de consulta pública global sobre a proposta de revisão das salvaguardas socioambientais, a fim de reunir comentários dos governos, sociedade civil e outros atores. A entrada em vigor de novas salvaguardas, mais flexíveis teriam sido propostas para "modernizar e consolidar políticas atualmente fragmentadas ou duplicadas", elevando a clareza e coerência entre elas, esclarecendo papéis e responsabilidades entre o Banco e seus clientes e respondendo a desafios emergentes nos campos social e ambiental ${ }^{18}$. Essa, inclusive, foi a premissa que conduziu o processo de consultas públicas que permitiram a organização a adotar, em agosto de 2016, o documento intitulado "New Environmental and Social Framework" ${ }^{\prime 19}$.

Especificamente em relação ao tema dos reassentamentos involuntários, o Banco entendeu que seria necessário estabelecer maior clareza sobre a própria relação com os Estados tomadores, assim como sobre os instrumentos de planejamento de reassentamento. Os Estados seriam chamados a desenvolver um plano de reassentamento ou plano de restauração de subsistência das comunidades afetadas, de modo enfrentar os efeitos adversos decorrentes da implementação dos projetos e identificados por meio da avaliação ambiental e social. Também de modo mais amplo, o Banco Mundial recomenda aos Estados evitar "despejos forçados", proporcionando às comunidades afetadas remédios legais para a proteção de direitos concernentes à posse e propriedade de seus bens/terras, com respeito ao devido processo legal e abstenção do "uso de força excessiva".

$\mathrm{Na}$ versão final do documento de 2016, constitutivo das novas políticas sobre salvaguardas socioambientais do Banco, o Conselho reconhece que alguns aspectos envolvendo os financiamentos e reassentamentos involuntários: possibilidade de "efeitos adversos" sobre comunidades deslocadas e comunidades anfitriãs, recebendo os deslocados; a necessidade de planejamento, de adoção de medidas apropriadas e de mitigação de danos, oferta de ampla informação e consulta às comunidades afetadas e mecanismos de compensação (BANCO MUNDIAL, 2016, p. 76 e ss).

\subsubsection{Seletividade de ações e atos de violação}

18 Informações do Banco Mundial em: http://consultations.worldbank.org/consultation/review-and-updateworld-bank-safeguard-policies.

19 Documento em: http://consultations.worldbank.org/consultation/review-and-update-world-bank-safeguardpolicies 
Além da questão dos deslocamentos forçados, outra parte da crítica diz respeito à seletividade das ações de organismos internacionais no campo das salvaguardas socioambientais. ZHOU (2012, p. 824) considera, por exemplo, que o compromisso do Banco Mundial com direitos humanos revela-se ocasional, "ad hoc, informal e sem diálogo com normas internacionais". Desse fato, com frequência, resultam reclamações por parte de estados e de organizações da sociedade civil contra a atuação do Banco. Assim, entre as possíveis soluções haveria espaço para adoção de um sistema de monitoramento de projetos, pautado na efetividade socioambiental das iniciativas de empréstimos setoriais e na avaliação de riscos de violação (ou potencial de violação) de normas de direitos humanos e ambientais.

No limite, parece existir um hiato entre o quadro de elaboração e cumprimento de salvaguardas socioambientais e a própria compreensão sobre o alcance e a observância das normas de proteção dos direitos humanos e do meio ambiente como objetivos centrais e obrigações “erga omnes” no Direito Internacional (ZHOU, 2012, p. 827) ${ }^{20}$. Tal política de salvaguardas, conforme comenta Zhou, permite que a sociedade civil, por meio do Painel de Inspeção, tenha acesso ao Banco e possa denunciar os riscos causados pelos projetos por ele financiados, de forma específica e direcionada, sem precisar recorrer a um fórum geral. Além disso, a autora aponta que esse posicionamento institucional demandaria análise da capacidade de o Estado devedor cumprir com as obrigações a respeito dos direitos humanos - em nível doméstico e internacional - e das maneiras de mitigar os impactos dos projetos.

O compromisso das instituições financeiras internacionais, manifesto em uma política de salvaguardas, deveria coincidir com as obrigações expressas no direito internacional dos direitos humanos de respeitar, cumprir e proteger direitos e garantias das populações locais afetadas, em projetos de financiamentos, bem como garantir que os Estados receptores/devedores respeitem as normas de jus cogens (ZHOU, 2012, p.834). Existem, no entanto, limites legais e institucionais para cumprimento das salvaguardas. Elas podem ser interpretadas como imposição do Banco Mundial aos Estados devedores e, ainda, o que parece mais problemático, podem dar

\footnotetext{
20 Assim se manifesta a autora: "The gap between recognition of human rights as values and human rights as legal obligations has driven continuing calls for an international human rights law safeguard policy, couched in similar terms to the current policy relating to environmental assessments, which requires consideration of both a borrowing state's domestic environmental legislation and its obligations under international environmental law and states that the Bank does not fund projects that contravene such obligations".
} 
margens à criação, pela organização, de certos padrões de direitos humanos, os quais seriam cumpridos devido à influência econômica por aquela exercida. A viabilidade das políticas de salvaguardas também é questionada pelo fato de que elas poderiam elevar o montante dos empréstimos, o que significaria maior endividamento por parte dos Estados receptores. No entanto, seria contraproducente o financiamento em situações que ameaçam o bem-estar das populações locais, ainda que isso significasse custos reduzidos (ZHOU, 2012, p. 834).

Da seletividade da orientação de políticas favoráveis aos direitos humanos à proteção de padrões ambientalmente sustentáveis, muitas das reações do Banco Mundial, as violações são tratadas por procedimentos internos da organização. É justamente nesse contexto que se inserem as atividades do Painel de Inspeção, como analisadas anteriormente. A efetividade dos mecanismos externos, contudo, é dificultada pelas imunidades de que o Banco, como organização, goza no direito interno dos Estados devedores ${ }^{21}$, além da dificuldade de serem utilizados instrumentos do direito internacional, como ações e reclamações perante tribunais e órgãos internacionais.

\subsubsection{Ofensiva pela interface entre obrigações financeiras e direitos humanos}

Existe mandato em curso das Nações Unidas para a avaliação dos efeitos do endividamento externo pelos Membros e outras obrigações financeiras internacionais sobre o exercício de direitos fundamentais, particularmente direitos econômicos, sociais e culturais. Esse aspecto tem sido bem expressado pela atuação do perito independente vinculado aos procedimentos especiais junto ao Conselho de Direitos Humanos, em cooperação com o Alto Comissariado para Direitos Humanos ${ }^{22}$.

A partir de um perito especializado, a ONU concentra missões de investigação e de análise em Membros que sejam, igualmente, tomadores de empréstimos para financiamento de projetos governamentais junto às organizações financeiras e agências de desenvolvimento. Com isso, a Organização pretende verificar de que forma os efeitos da dívida externa e as políticas

21 Cf., por exemplo, a Convenção sobre Privilégios e Imunidades das Agências Especializadas das Nações Unidas, de 21 de novembro de 1947 (incorporada ao ordenamento jurídico brasileiro pelo Decreto $1^{\circ} 52.288$, de 24 de julho de 1963). Nos termos do Art. $1^{\circ}$ da Convenção, Fundo Monetário Internacional e Banco Mundial estão incluídos no rol das organizações com imunidade e privilégios.

22 Informações institucionais

http://www.ohchr.org/EN/Issues/Development/IEDebt/Pages/IEDebtIndex.aspx

em: 
adotadas para enfrentá-los, do ponto de vista estrutural, afetam o pleno exercício de direitos humanos pelas populações locais. Outra preocupação é a de determinar se a dívida externa afeta a capacidade dos Membros de formular e implementar políticas públicas e programas, incluindo controle sobre situação orçamentária interna para dar conta das demandas mais básicas de promoção da concretização de direitos sociais ${ }^{23}$. É papel do Perito Especial, igualmente, verificar a viabilidade das medidas adotadas pelos governos, setor privado e as instituições financeiras internacionais para mitigar os resultados potencialmente prejudiciais dos financiamentos sobre países em desenvolvimento, especialmente os países mais pobres e aqueles altamente endividados. Os trabalhos no âmbito do Alto Comissariado também cuidam de quantificar normas mínimas para consecução das Metas do Milênio para o Desenvolvimento e o aperfeiçoamento de sistema de consultas pelas partes interessadas relativamente ao mandato do Perito Especial e suas possíveis linhas de atuação. ${ }^{24}$

A recente Resolução 25/9 do Conselho de Direitos Humanos, de 15 de abril de $2014,{ }^{25}$ estabelece, ao Perito Independente, a atribuição de "continuar a considerar o impacto dos fluxos financeiros ilícitos sobre o exercício dos direitos humanos como parte de sua ou seu mandato". Por força do mandato vigente, o Perito realiza missões nos países tomadores de empréstimos ou beneficiários de doações para analisar os efeitos da dívida externa, além de promover diálogos com o governo, instituições financeiras internacionais (como FMI, Banco Mundial e BID), agências especializadas da ONU e organizações da sociedade civil. Da mesma forma, são produzidos estudos e recomendações práticas para os países-alvos das missões.

Esse processo teve início ainda em 2004, quando a então Comissão de Direitos Humanos encarregou o perito independente de elaborar diretrizes gerais a serem observadas, pelos Estados e pelas instituições financeiras públicas e privadas, nacionais e internacionais, quanto à tomada de decisão e execução de o pagamento da dívida e programas domésticos de reforma estrutural, incluindo os decorrentes de renegociação de dívida externa. A preocupação inicial da Comissão seria a de assegurar que o cumprimento de obrigações decorrentes de

\footnotetext{
23 Poderíamos falar aqui em "efeitos constritivos", que afetam o pleno exercício de direitos, e "efeitos restritivos", que afetam capacidades institucionais dos estados receptores.

24 Informações institucionais em

http://I.ohchr.org/EN/Issues/Development/IEDebt/Pages/IEDebtIndex.aspx>.

25 A Resolução foi aprovada por 30 votos favoráveis, dentre os quais o do Brasil, e contra os 14 desfavoráveis e 3 abstenções. Votaram contrariamente: Alemanha, Áustria, Estados Unidos de América, Estônia, Macedônia, França, Irlanda, Itália, Japão, Montenegro, Reino Unido, República Checa, República da Coréia e Romênia.
} 
empréstimos internacionais não prejudicasse as obrigações dos Membros de promoção e respeito dos direitos econômicos, sociais e culturais fundamentais, tais como as estabelecidas nos principais tratados de direitos humanos.

O processo negociador, no âmbito do Conselho de Direitos Humanos, desenvolveu-se fundamentalmente em duas frentes. A primeira, em função de recomendações sobre o comportamento dos Membros, setores privados e instituições financeiras internacionais relativamente à compatibilização entre a responsabilidade principal de promoção do desenvolvimento econômico, social e cultural e a independência dos governos em relação a “imposições externas específicas para política econômica”, como bem expressa a Resolução $11 / 5$, de 17 de junho de $2009 .^{26}$ A segunda frente diz respeito à elaboração de normas articulando endividamento externo, empréstimos internacionais e observância das normas internacionais de direitos humanos.

Nessa linha, em junho de 2012 foram adotados os Princípios Diretrizes sobre Dívida Externa e Direitos Humanos ${ }^{27}$ após trabalhos de consultas do Perito Especial, com os quais os Membros das Nações Unidas chegaram a uma tentativa de denominador comum sobre o tema dos empréstimos internacionais. O objetivo primordial dos Princípios seria o "de equilibrar as obrigações contratuais do Estado devedor e credor, decorrentes de acordos da dívida externa, e também as obrigações internacionais de respeitar, proteger e fazer cumprir todos os direitos humanos, particularmente os direitos econômicos, sociais e culturais". ${ }^{28}$ Da mesma forma, os Membros convencionaram as prioridades temáticas a serem verificadas na implementação de obrigações por Estados e organizações internacionais no campo dos financiamentos internacionais:

26 Informação disponível em: <http://ap.ohchr.org/documents/E/HRC/resolutions/A HRC RES 11 5.pdf >. O Brasil votou a favor da Resolução.

27 UN, A/HRC/20/23. Report of the Independent Expert on the effects of foreign debt and other related international financial obligations of States on the full enjoyment of all human rights, particularly economic, social and cultural rights, as of 10/04/2012 (Relatório "Lumina"). Disponível em: <http://daccessods.un.org/TMP/8409378.52859497.html> . A Resolução 20/10 de 18 de julho de 2012 aprovou os princípios, com 31 votos favoráveis dos Membros, tendo sido contrários os seguintes: Áustria, Bélgica, República Checa, Hungria, Itália, Polônia, República da Moldovia, Romênia, Espanha, Suíça, Estados Unidos da América; e as abstenções: Chile, Costa Rica, México, Noruega e Peru.

28 Do original: "2. The overriding aim of these principles is to balance the debtor and creditor State's contractual obligations arising from external debt arrangements and both debtor and creditor's international legal obligations to respect, protect and fulfil all human rights, particularly economic, social and cultural rights". 
(a) observância de aspectos preventivos da política tributária e de gestão da dívida externa para evitar potenciais efeitos negativos dos empréstimos sobre a efetividade de direitos fundamentais;

(b) observância das normas de direito internacional dos direitos humanos no contexto da reestruturação da dívida e redução da dívida dos Estados e seus governos/entes;

(c) adoção de boas práticas para redução dos efeitos negativos de programas de ajuste econômico e reestruturação da dívida (e.g. planos e pacotes de austeridade) sobre direitos humanos (HRCH, 2015);

(d) observância de normas de proteção dos direitos humanos em arbitragens de litígios entre Estados e investidores, previstas em tratados bilaterais de investimento;(e) controle prévio de concessão de empréstimos a Estados envolvidos em violações de direitos humanos ${ }^{29} ; \mathrm{e}$

(f) análise de impacto dos fluxos financeiros ilícitos em matéria de direitos humanos ${ }^{30}$.

Apesar do caráter programático e não vinculante no sentido formal (se entendidos como fontes de 'soft law' ou normas narrativas), os Princípios Diretrizes sobre Dívida Externa e Direitos Humanos de 2012 remetem a uma importante vertente operacional do direito internacional econômico. Ela é centrada no objetivo de equalização de interesses de Estados, seus governos, e organismos financeiros multilaterais, de um lado, e todos outros atores envolvidos e interessados no processo ('stakeholders'), como comunidade, grupos, indivíduos, organizações da sociedade civil em regiões e localidades potencialmente afetadas pelos projetos financiados. Por isso mesmo, o conjunto das decisões do Conselho de Direitos Humanos da ONU, além de princípios e diretrizes por ele adotados, em sua normatividade, reforçam a

29 UN Human Rights Council. A/HRC/28/59. Report of the Independent Expert on the effects of foreign debt and other related international financial obligations of States on the full enjoyment of human rights, particularly economic, social and cultural rights, Juan Bohoslavsky - Report on financial complicity: lending to States engaged in gross human rights violation. Disponível http://www.ohchr.org/EN/Issues/Development/IEDebt/Pages/IEDebtIndex.aspx.

30 UN Human Rights Council. A/HRC/28/60. Illicit financial flows, human rights and the post-2015 development agenda, Interim study by the Independent Expert on the effects of foreign debt and other related international financial obligations of States on the full enjoyment of all human rights, particularly economic, social and cultural rights, Juan Pablo Bohoslavsky. Disponível em: http://www.ohchr.org/EN/Issues/Development/IEDebt/Pages/IEDebtIndex.aspx ${ }^{31} \quad$ Cf. por exemplo a Resolução 11/5 do Conselho de Direitos Humanos, de 17 de junho de 2009, para 5: "Recalls that every State has the primary responsibility to promote the economic, social and cultural development of its people, and, to that end, has the right and responsibility to choose its means and goals of development and should not be subject to external specific prescriptions for economic policy." 
indissociabilidade entre salvaguardas socioambientais e operações de financiamento e empréstimos internacionais.

É evidente que todo o trabalho já desenvolvido pelo Conselho de Direitos Humanos da ONU passa por uma preocupação central e que raramente é capturada pelo debate público internacional ou mesmo materializadas por políticas legislativas e práticas internas dos Estados receptores de financiamentos internacionais. Os governos continuam responsáveis primariamente pela promoção dos direitos econômicos, sociais e culturais. Os Estados têm o direito e a responsabilidade de escolha sobre seus instrumentos e objetivos de desenvolvimento, sem que possam ser submetidos a quaisquer diretrizes externas específicas de política econômica. Tratase de discricionariedade ainda subsistente no conjunto da implementação das obrigações internacionais assumidas pelos Estados, ainda refletida na capacidade institucional de Estados receptores de financiamentos de adotar de políticas públicas orientadas para observância de direitos humanos e proteção do meio ambiente.

No limite, isso valeria para legitimar determinada posição ou prática de distensão ou moratória do Estado em relação a ditames estabelecidos por organizações internacionais e as agências de risco (rating agencies) tipicamente operantes no hemisfério norte, e que muitas vezes desconsideram compromissos (sociais, econômicos e culturais) assumidos por Estados devedores/receptores em suas constituições domésticas ${ }^{31-32}$ Não diferentemente, os mais afetados seriam, no contexto de relações econômicas internacionais assimétricas, os países mais pobres, de menor desenvolvimento relativo e países com economias em transição.

Por outro lado, parece também evidente que os Estados, em consenso com organizações internacionais, teriam condições de empreender programas de reformas econômicas com objetivos centrados nos Objetivos do Desenvolvimento Sustentável (ODMs) das Nações Unidas para o Milênio ${ }^{33}$. Do ponto de vista da execução e adimplemento dos acordos com organismos financeiros e bancos de fomento, a reestruturação de dívidas é uma saída que deve ser formulada com conhecimento do público e transparência. Isso requer, desde a perspectiva doméstica, a criação de mecanismos de consulta, arranjos legislativos e institucionais para maior

31 Cf. por exemplo a Resolução 11/5 do Conselho de Direitos Humanos, de 17 de junho de 2009, para 5: "Recalls that every State has the primary responsibility to promote the economic, social and cultural development of its people, and, to that end, has the right and responsibility to choose its means and goals of development and should not be subject to external specific prescriptions for economic policy."

$32<$ http://ap.ohchr.org/documents/E/HRC/resolutions/A_HRC_RES_11_5.pdf >.

33 A esse respeito, ver: http://www.un.org/sustainabledevelopment/sustainable-development-goals/ 
envolvimento da sociedade civil e comunidades eventualmente afetadas pelos projetos financiados ${ }^{34}$.

O Conselho de Direitos Humanos também alinhou entendimentos e recomendações quanto à adoção de práticas recíprocas entre organizações internacionais e estados tomadores de empréstimos no contexto das operações de financiamento e projetos governamentais:

a) mecanismos de aplicação e avaliação de estratégias, políticas e programas, bem como de acompanhamento e controle pelos governos, da implementação operacional de projetos financiados e da execução de acordos de empréstimo concluídos com as organizações internacionais;

b) integração entre questões de políticas macroeconômicas e financeiras e a realização plena de objetivos do desenvolvimento do estado tomador dos financiamentos, de modo equitativo e consistente;

c) prioridade aos contextos nacionais e demandas dos países devedores para alocação de recursos de tal modo que sejam favoráveis ao desenvolvimento equilibrado e concretização dos direitos fundamentais;

d) obrigação compartilhadas dos credores, em especial as instituições financeiras internacionais, e devedores de considerar a avaliação de impacto de direitos humanos relativamente aos projetos de desenvolvimento e contratos de empréstimo ${ }^{35}$; e reafirmação de que o exercício e a concretização de direitos fundamentais de indivíduos e populações dos países devedores, de alimentação, moradia, vestuário, emprego, serviços de saúde e meio ambiente saudável não estejam subordinados à implementação de

\footnotetext{
34 Cf. a recomendação contida no item 15 da Resolução 11/5 do Conselho de Direitos Humanos, de 17 de junho de 2009 e retomada na Resolução 28/14, de 23 de março de 2015, sobre os efeitos do endividamento externo e obrigações financeiras internacionais dos Estados sobre o pleno direitos humanos, particularmente direitos econômicos, sociais e culturais: "Stresses the need for the economic reform programmes arising from foreign debt to be country-driven and for any negotiations and conclusion of debt relief and new loan agreements to be formulated with public knowledge and transparency, with legislative frameworks, institutional arrangements and mechanisms for consultation being established to ensure the effective participation of all components of society" (c.f UN Human Rights Council, $\mathrm{A} / \mathrm{HRC} / 28 / \mathrm{L} .14$, The effects of foreign debt and other related international financial obligations of States on the full enjoyment of all human rights, particularly economic, social and cultural rights. 23 March 2015).

$35 \quad$ Cf. Item 19 da Resolução 11/5 do Conselho de Direitos Humanos, de 17 de junho de 2009.
} 
políticas de ajustes estruturais, programas de crescimento e reformas econômicas emergentes da dívida ${ }^{36}$.

Essas diretrizes parecem evidenciar a preocupação mais ampla das Nações Unidas com a falta de comunicação e sintonia entre as práticas das organizações internacionais, em particular quanto aos empréstimos concedidos aos países mais pobres do globo em projetos locais e regionais, e a observância das normas internacionais de proteção dos direitos humanos e do meio ambiente (CLARK, 2002, p. 212). Os casos relatados e também levados ao Painel de Inspeção do Banco Mundial, em seus anos de existência, acenam para questões práticas revelando a medida pela qual interesses de grupos, comunidades e indivíduos são frontalmente afetados pelas condicionantes estabelecidas nas operações e acordos concluídos entre as organizações e os estados.

Por isso mesmo, a intersecção entre direitos humanos, meio ambiente e financiamentos internacionais enfatiza as tensões próprias da agenda da governança das organizações e o relacionamento com estados. As salvaguardas socioambientais, como aplicadas pelo Banco Mundial, representam atualmente desafios para o trade-off ainda não superado entre benefícios econômicos e proteção ambiental e dos direitos humanos e as falhas institucionais da própria organização, que dá prevalência para uma cultura propriamente corporativa (ZHOU, 2012, p. 836).

A nova tendência narrativa em torno de preocupações sobre proteção aos direitos humanos que se verifica no âmbito institucional do Bando Mundial é apontada por Zhou como oportunidade para a estruturação de um sistema aprimorado de salvaguardas socioambientais. A despeito dos desafios que tradicionalmente são impostos aos direitos humanos, a autora considera que uma efetiva política de salvaguardas é possível a partir de um arranjo cuidadoso, the exercise of the basic rights of the people of debtor countries to food, housing, clothing, employment, education, health services and a healthy environment cannot be subordinated to the implementation of structural adjustment policies, growth programmes and economic reforms arising from the debt."). 
acompanhado de avaliações mais amplas e precisas dos projetos a serem financiados e, ainda, de vontade política (ZHOU, 2012, p. 840).

É precisamente nessa linha de atuação que haveria espaço para neofederalismo das organizações financeiras internacionais e as Nações Unidas na formulação de princípios não de "boa governança", mas de justa governança (fair governance). No próximo item, são abordadas algumas questões envolvendo o Brasil e reflexos socioambientais decorrentes de financiamentos internacionais. Sem pretensão de se esgotar o tema, a análise proposta levanta preocupações consistentes com as distintas proporções em que o Estado brasileiro tem enfrentado o tema e como essas preocupações poderiam aperfeiçoar a aplicação concreta das salvaguardas socioambientais.

\section{Brasil, financiamentos internacionais e reflexos socioambientais}

Há muito tem sido divulgado que o Estado brasileiro, por distintos de seus entes federativos (União, Estados, Municípios e Distrito Federal), busca oportunidades de financiamento de projetos governamentais junto a organizações internacionais e agências multilaterais de fomento, como no Banco Mundial e Banco Interamericano de Desenvolvimento, com consideráveis volumes de empréstimos e consequente endividamento externo (SENADO FEDERAL, 2013) ${ }^{37}$.

Em 2012, o Brasil comprometeu-se por aproximadamente US\$ 3,267 milhões, tendo reduzido o volume contratado nos anos subsequentes (de US\$ 3,076 milhões em 2013; e US\$ 2,034 milhões em 2014) (Figura 1.1). Considerando os setores-alvos dos projetos financiados pelo Banco Mundial ao Brasil, destacam-se entes subnacionais (estados e municípios), agrícola,

37 A Advocacia Geral da União (2013), em manual sobre os financiamentos externos do Brasil, de 2013, aponta como fontes de recursos internacionais, além do Banco Mundial e o do Interamericano de Desenvolvimento, a Corporação Andina de Fomento (CAF), o Fundo Internacional para o Desenvolvimento da Agricultura (FIDA), Fundo Financeiro para o Desenvolvimento da Bacia do Prata (FONPLATA), o Fundo Global para o Meio Ambiente (GEF), o Banco Japonês para Cooperação Internacional (JBIC), o Kreditanstalt Für Wiederaufbau (KFW) e a Agência Francesa de Desenvolvimento (AFD). Ainda sobre balanço de operações e controle interno feito pela CGU sobre Executivo Federal em 2009, ver: <http://www.cgu.gov.br/assuntos/auditoria-e-fiscalizacao/avaliacao-dagestao-dos-administradores/prestacao-de-contas-do-presidente-da-republica/arquivos/2009/210.pdf> 


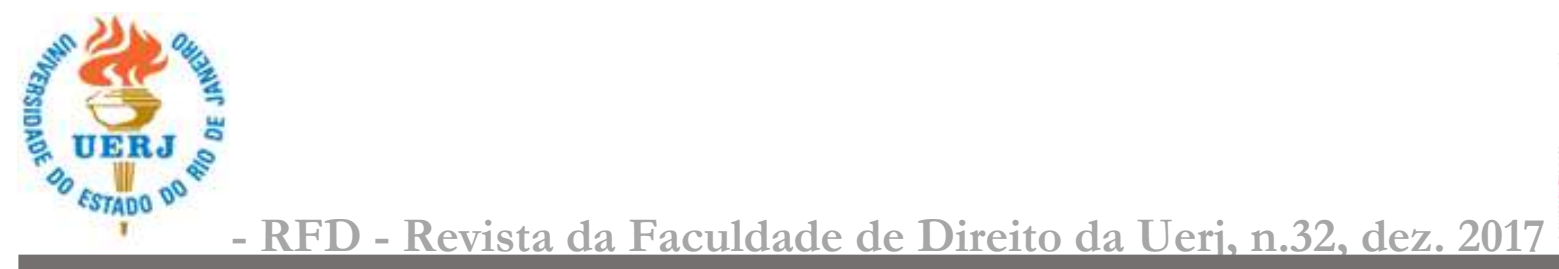

administração federal, serviços sociais e água, saneamento básico, abastecimento e proteção contra enchentes; e saúde ${ }^{38}$.

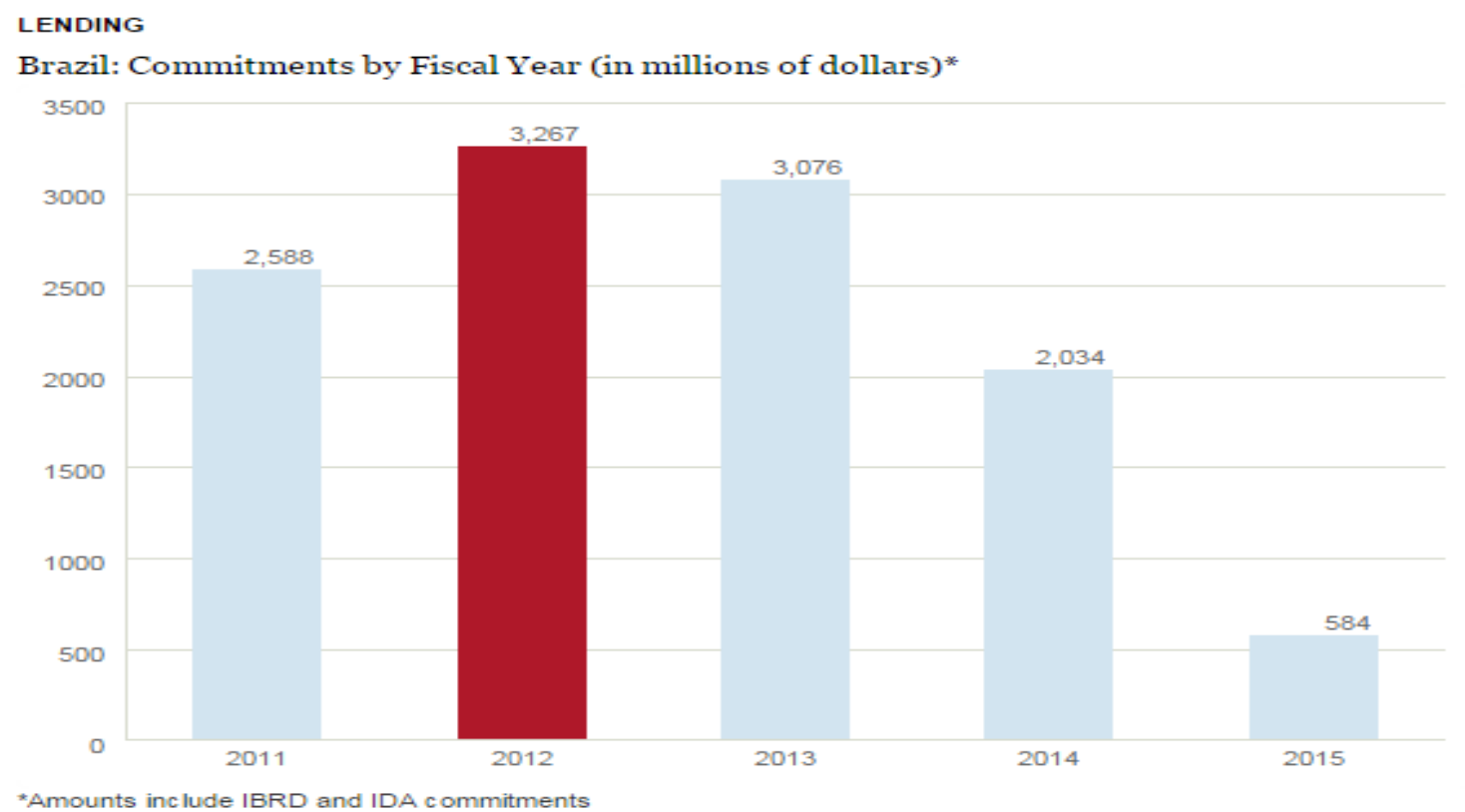

No Brasil, as operações de empréstimos internacionais são enquadradas como atos de endividamento dos entes federativos no Brasil, incluindo União, Estados, Municípios e Distrito Federal). Como se sabe, a conclusão dessas operações deve ser submetida à aprovação pelo Senado, em conformidade com a competência prevista pela Constituição Federal em seu Art.54, inciso V, e com os limites e procedimentos estabelecidos pela Resolução n. 43/200139. Contudo, muitas delas, especialmente as originadas por entes não-centrais - estado e municípios - deixam de ser apreciadas a fundo pelo Senado; com certa frequência, outras são apenas auditadas segundo parâmetros de controle interno, levados a cabo pela Controladoria Geral da União, quando apresentem alguma relação com orçamento da União, ou, localmente, por Controladorias gerais dos estados e municípios ${ }^{40}$.

\footnotetext{
38 Dados do Banco Mundial (2015).

39 “Art. $3^{\circ}$ Constitui operação de crédito, para os efeitos desta Resolução, os compromissos assumidos com credores situados no país ou no exterior, em razão de mútuo, abertura de rédito, emissão e aceite de título, aquisição financiada de bens, recebimento antecipado de valores provenientes da venda a termo de bens e serviços, arrendamento mercantil e outras operações assemelhadas, inclusive com o uso de derivativos financeiros".

40 Atualmente, a Clínica de Práticas e Pesquisa em Diplomacia Federativa e Cooperação Internacional, da Universidade Federal de Minas Gerais, tem se dedicado a examinar as variações dessas operações e do perfil do
} 
Por essas razões quase intuitivas, a prática do Estado brasileiro quanto às operações de empréstimos internacionais e a correspondente ação dos organismos multilaterais, como o Banco Mundial, abriram espaço para maior escrutínio por parte da opinião pública e especialistas nas últimas décadas; entre as questões, destacam-se preocupações relativas à real efetividade e viabilidade dos projetos e a necessidade de ajustamento dessas ações a objetivos e políticas públicas envolvendo proteção do meio ambiente e direitos humanos das regiões atingidas pela implementação desses projetos.

Em junho de 1995, o Painel de Inspeção do Banco Mundial foi acionado para analisar os desdobramentos do Projeto de Gestão de Recursos Naturais e Plano Agropecuário e Florestal de Rondônia - PLANAFORO ${ }^{41}$, a partir da iniciativa de organizações não governamentais representantes das comunidades locais afetadas pelo projeto, cujo financiamento havia sido aprovado em 17 de março de 1992. O pedido para abertura de investigação formal baseou-se na alegação de que a execução do PLANAFORO teria contribuído para o desmatamento local e degradação ambiental, ainda que, no mérito, o projeto tivesse por finalidade a proteção de recursos da floresta e dos ecossistemas circundando as comunidades afetadas, e corrigir inconsistências de um programa anterior financiado pelo Banco, o POLONOROESTE.

Embora reconhecendo os danos ambientais desencadeados pelo projeto, além dos prejuízos impostos às comunidades que, na verdade, deveriam ter sido beneficiadas, o Banco considerou apenas a responsabilidade do Estado devedor, no caso o Brasil, por falhas na execução do projeto. Em tese, o Painel de Inspeção sinalizava para o fato de que os investimentos na criação de áreas protegidas, reformas institucionais e estudos na área ambiental teriam sido insuficientes e se desenvolvido de modo muito lento por parte do Estado receptor, violando dispositivos do acordo de empréstimo entre o governo e o Banco Mundial (NINIO, 2009, p. 66).

O Conselho Diretor rejeitou as recomendações formuladas pelo Painel, solicitando-lhe revisões adicionais, as quais foram realizadas no curso da investigação, com a confirmação das recomendações anteriormente feitas. Em 1997, o órgão máximo novamente rejeitou o relatório

endividamento dos entes federados brasileiros, dentro da experiência brasileira recente. Sobre o projeto, ver: http://www2.direito.ufmg.br/cdf/

\footnotetext{
41 Informações $\quad$ sobre $\quad$ o $\quad$ projeto disponíveis $\quad$ em: http://documents.worldbank.org/curated/en/970341468015879255/text/NonAsciiFileName0.txt $>\quad$ e $<$ http://documents.worldbank.org/curated/en/785201468229178280/text/ICR11260P058501IC0disclosed08131091.tx $\mathrm{t}>$. Acesso em 28 de novembro de 2016.
} 
final do Painel, com o que a investigação não foi admitida na Organização, reiterando-se o argumento de que a falta de gerenciamento adequado dos recursos transferidos pelo Banco para o Estado brasileiro teria sido a principal para os graves danos ambientais decorrentes do projeto $^{42}$.

O segundo caso de destaque refere-se ao Reassentamento de Itaparica e Projeto de Irrigação (Itaparica Resettlement and Irrigation Project) em Bahia e Pernambuco, com a reclamação apresentada, em março de 1997, pela Coordenadoria Geral do Polo Sindical do Submédio São Francisco representando a comunidade de atingidos (BANCO MUNDIAL, 1997a). O acordo de empréstimo firmado com o Banco Mundial datava de 16 de novembro de 1987, base para que a coletividade de 6 mil camponeses, deslocados pelas obras financiadas, alegasse violação de direitos humanos no processo de reassentamento. Segundo o relatório, a população teria sido involuntariamente transferida por força das construções da Hidrelétrica de Itaparica (BANCO MUNDIAL, 1997b).

O Painel de Inspeção requereu permissão, ao Conselho Diretor, para investigar o caso, que o rejeitou, justificando sua decisão no fato de que o Estado brasileiro teria se comprometido com novos investimentos no projeto desenvolvido, pois os recursos transferidos pelo Banco já teriam sido praticamente utilizados; e na manutenção das ações de monitoramento do projeto por parte da própria Organização. Outro caso em comento é relativo ao Projeto-Piloto de Reforma Agrária e Redução da Pobreza (Land Reform and Poverty Alleviation Pilot Project), com reclamação apresentada ao Painel de Inspeção em dezembro de 1998 (BANCO MUNDIAL, $1999)^{43}$.

Nele, as requerentes, diversas associações representantes de trabalhadores rurais, entidades religiosas, como a Pastoral da Terra e a Cáritas Brasileira, solicitaram investigação formal, pelo Painel de Inspeção, dos danos decorrentes da implementação de projeto financiado pelo Banco Mundial, com empréstimo concedido em abril de 1997. O projeto tinha como objetivo a redução de bolsões de pobreza nas zonas rurais, a partir da criação da "Cédulas da Terra", com o financiamento de lotes, assistência técnica e oferta de insumos aos agricultores

42 Segundo a observação de NINIO (2009, p.66), o caso PLANAFLORO, ainda que não tivesse sido objeto de investigação formal, desencadeou reformulações no projeto original, a fim de dar-lhe maior efetividade.

43 Brazil - Land Reform and Poverty Alleviation Pilot Project: Report and Recommendation on the Request for Inspection. Washingto/DC: World Bank. 1999. Disponivel em: <http://documents.worldbank.org/curated/en/1999/05/3665693/brazil-land-reform-poverty-alleviation-pilotproject-request-1-report-recommendation-request-inspection> 
mais desfavorecidos. De acordo com a representação, a falta de efetiva assistência técnica e financeira, às comunidades afetadas, comprometeria a sustentabilidade do projeto, além de frustrar os propósitos de combate à pobreza e reforma agrária. Igualmente, as condicionantes do projeto financiado, como cláusulas de amortização de empréstimo aos agricultores, resultariam em prejuízos aos beneficiários. Em duas oportunidades de análise, considerando que duas reclamações foram reunidas - a de janeiro e a de setembro de 1999-, o Painel não procedeu à recomendação de investigação. Entendeu inexistirem requisitos para o procedimento, a saber, evidências de dano e omissão das reclamantes de estabelecer consultas com a gerência do Banco Mundial, com o objetivo de solucionar, preliminarmente, as objeções relativas ao projeto (BANCO MUNDIAL, 1999) $)^{44}$.

Mais recentemente, em 2006, o Painel foi chamado a apreciar o pedido de investigação sobre o Projeto de Biodiversidade do Paraná (Parana Biodiversity Project), cujo financiamento, concedido pelo Banco Mundial, havia sido aprovado em maio de 2002 (BANCO MUNDIAL, 2002). As Requerentes, organizações não governamentais atuantes no Estado do Paraná, afirmavam que a aprovação do Projeto alcançaria "uma expectativa sem precedentes e muito positiva" quanto à preservação da biodiversidade local. De acordo com o pedido, a conservação da biomassa da Araucária e da Mata Atlântica seria de prioridade no Estado do Paraná, sobretudo porque aquela estaria reduzida a 0,8 por cento de sua área original. "Alterações metodológicas" feitas durante a implementação do projeto após aprovação, todavia, teriam resultado em uma mudança das atividades, frustrando a realização dos objetivos originais, com perdas significativas. O Painel verificou que, depois de notificadas, as autoridades locais passaram a agir de modo coerente com o projeto inicial e se comprometeram a adotar medidas que envolvessem ONGs e a sociedade civil em sua execução. Por isso, o Painel não solicitou investigações mais detalhadas e encerrou sua atuação (BANCO MUNDIAL, 2006).

Os três casos descritos acima apontam para algumas evidências que não poderiam ser afastadas dentro de uma análise sobre as assimetrias envolvendo os graus de responsabilidade internacional entre estados e organizações internacionais no contexto de financiamento de projetos governamentais com impactos socioambientais. A primeira diz respeito aos limites

44 Brazil - Land Reform and Poverty Alleviation Pilot Project: Report and Recommendation on the Request for Inspection. Washingto/DC: World Bank. 1999. Disponivel em: <http://documents.worldbank.org/curated/en/1999/05/3665693/brazil-land-reform-poverty-alleviation-pilotproject-request-1-report-recommendation-request-inspection> 
postos aos órgãos de monitoramento, como revela a atuação do Painel de Inspeção do Banco Mundial. Eles frequentemente são submetidos a crivos decisórios de instâncias superiores, sem a possibilidade de continuação de procedimentos de investigação ou acompanhamento em casos admitidos como sensíveis.

A segunda refere-se à própria história, controvertida, de exposição das comunidades locais, em países beneficiários de fundos e financiamentos internacionais de projetos, a riscos potenciais e danos socioambientais. Esse aspecto se manifesta, por exemplo, pelo contato de indivíduos e grupos com produtos tóxicos resultantes do processo industrial; o deslocamento forçado de comunidades em áreas de grandes construções, como barragens, reservatórios e hidrelétricas; e a ausência de monitoramento da implementação de projetos financiados (BUNTAINE, 2012, p. 102).

\section{Responsabilidade compartilhada entre estados e organizações Internacionais e a inclusão dos estudos de impactos em direitos humanos e recomendações}

As experiências demonstradas pelos projetos governamentais financiados por organismos, bancos de desenvolvimento e agências de fomento internacionais nas últimas quatro décadas corroboram as preocupações da sociedade civil internacional, academia e especialistas em políticas públicas e devem servir como base para revisão de princípios e regras de Direito Internacional, particularmente no campo da responsabilidade socioambiental.

Se por um lado, as teorias gerais e vertentes da responsabilidade internacional do estado e organizações internacionais têm sido bem-sucedidas em trabalhos de elaboração normativa, como levados a cabo pela Comissão de Direito Internacional da ONU, por outro, as estruturas para responsabilização dos sujeitos por ilícitos praticados no curso de operações de financiamento de projetos governamentais restam absolutamente deficitárias ${ }^{45}$. Talvez seja prudente, do ponto de vista do Direito Internacional, admitir as consideráveis assimetrias de compartilhamento de responsabilidades entre Estados e organizações internacionais relativamente à implementação e monitoramento desses projetos. Entre as possíveis soluções,

45 Retomamos, aqui, a crítica formulada por CLARK (2002, p.212), relativamente à sutil transferência de responsabilidades para os estados receptores de empréstimos ou beneficiários de linhas de financiamento de projetos, que acabam permanecendo com a tarefa de monitorar e fiscalizar todo tipo de atividade que seria resultante da concessão/outorga. 
haveria o desejo de consolidação de regime de obrigações multilaterais e bilaterais envolvendo responsabilidade solidária entre doadores e receptores de empréstimos e financiamentos de projetos, com a possibilidade de adoção de medidas preventivas e repressivas em relação a conduta dos sujeitos.

Entre as medidas preventivas, encontram-se: (i) a obrigatoriedade de condução de estudos de impactos dos projetos em matéria socioambiental (estudos que fazem convergir/interagir elementos de análise em matéria de direitos humanos e proteção do meio ambiente) em linha com o direito internacional e direito constitucional dos estados; (ii) imposição de consultas públicas (mandatórias/obrigatórias) como pressuposto de admissibilidade dos empréstimos internacionais objetivados, dentro de parâmetros de viabilidade e exequibilidade para validação.

Como medidas repressivas, destacam-se: i) interrupção do financiamento pelas organizações, ii) moratória ou modulação na implementação dos projetos segundo critérios $\operatorname{corretivos}^{46}$; iii) pagamento de indenizações por fundos internacionais às comunidades afetadas, constituídos a partir de recursos securitários alocados entre doadores e receptores ou por percentuais deduzidos do montante total do empréstimo concedido; iv) inclusão de Estados e organizações em lista vermelha (red list) dos órgãos de monitoramento de direitos humanos nos sistemas das Nações Unidas e sistemas regionais (Cortes Europeia, Africana e Interamericana de Direitos Humanos).

Aspecto relevante nesse contexto, portanto, seria o paralelismo estabelecido entre estudo de impactos ambientais dos projetos e estudo de impactos de direitos humanos (também chamado "human rigths impact assessment" - HRIA) (HARRISON, 2011, p.162 e ss; e LANDMAN, 204, p.906 e ss). Trata-se de mecanismo de avaliação fundado nos padrões de proteção consagrados no arcabouço normativo internacional vigente em matéria de direitos humanos, tais como as normas da Declaração Universal dos Direitos Humanos de 1948, os Pactos das Nações Unidas de 1966, e tratados regionais relevantes (e.g. Convenção Europeia de 1950, a Convenção Americana de 1969 e a Convenção Africana de 1984). Essa modalidade de

46 Essas duas opções são vislumbradas por BRADLOW (1993, p.66), contudo em distintas percepções. O autor sugere a possibilidade de manutenção do financiamento e repasse de recursos, com a assunção de benefícios a serem percebidos gradualmente com a implementação do projeto, e a decisão pela concessão do financiamento, condicionada a garantias de que os indivíduos possam defender administrativa e judicialmente seus direitos. CLARK (2202, p.216), por seu turno, enfatiza a defesa da moratória especificamente para projetos envolvendo deslocamento forçado de comunidades. 
estudo de impactos busca examinar de que modo os projetos financiados a partir de empréstimos tomados em organizações, bancos e agências internacionais observam padrões de proteção de direitos humanos potencialmente afetados pela execução, tendo como base a conexão com a proposta a ser desenvolvida no projeto.

Em um EIDH, parâmetros de direitos humanos figuram como objetivo da avaliação e como diretrizes para o estudo (VILLAROMAN, 2011). A elaboração de um EIDH, em processos envolvendo a contratação de empréstimos entre Estados e organizações internacionais, é suportado pela aplicação da Resolução 11/5 do Conselho de Direitos Humanos da ONU. A Resolução, como visto anteriormente (item 2.1.3 supra), reconhece as possíveis externalidades negativas advindas de financiamentos internacionais sobre o ambiente de implementação e observância das obrigações de proteção dos direitos humanos nos sistemas domésticos de países devedores ${ }^{47}$.

Por que então, os EIDHs teriam maior apelo entre os mecanismos de avaliação de impactos e monitoramento? Primeiramente, pela pressão internacional em relação à efetividade de políticas de observância/adequação ("compliance") com padrões de proteção de direitos humanos. No contexto dos empréstimos internacionais, tantos os Estados doadores e receptores como as organizações internacionais teriam, no mínimo, a obrigação geral de não dar causa às violações a direitos humanos de comunidades locais afetadas pela execução de projetos financiados, quer direta ou indiretamente.

Segundo, porque os EIDHs necessariamente forçam a consolidação de indicadores e padrões normativos transnacionais a partir de uma zona de interface entre direito internacional econômico (na disciplina dos empréstimos internacionais contraídos por Estados ou da abertura de linhas de financiamento por organismos internacionais, agências e bancos estrangeiros) e o direito internacional dos direitos humanos.

Se entre os principais argumentos desfavoráveis à avaliação de impactos em matéria de direitos humanos estariam o tempo e os custos associados à elaboração de estudos, relatórios

47 Determinados precedentes, como examinado por VILLAROMAN (2011, p.5), alertam para a situação de violações sistemáticas de direitos humanos decorrentes de empréstimo internacionais: na África, por exemplo, recursos de Banco Chinês de Desenvolvimento, acessados por governos, tem contribuído para ações e programas que levam ao deslocamento forçado de populações locais e degradação ambiental; no Camboja, as mesmas operações de empréstimos internacionais, destinadas para construção de uma barragem, não passaram por qualquer análise mais detalhada em termos de impactos socioambientais. Do projeto resultaram o deslocamento de comunidades nativas e desaparecimento de sítios arqueológicos. 
técnicos e outros documentos, a opção deve ser a de estabelecer setores prioritários para os EIDHs, com compartilhamento de responsabilidades. Nesse caso, as organizações internacionais e bancos de fomento deveriam se concentrar no escrutínio técnico e normativo de projetos que apresentem fortes indícios de violações de direitos humanos, seja pelo histórico dos países devedores, seja pelo objeto do financiamento, como por exemplo, nos setores de aquisição de armas, grandes obras de infraestrutura, exploração mineral e extrativismo, saneamento e energia (especialmente petróleo, gás e hidrelétricas) (VILLAROMAN, 2011, p. 5; e CLARK, 2002, p. 212). Estados, por seu turno, teriam como atribuição central a prestação de todas as informações necessárias para a condução dos estudos de impacto.

Do ponto de vista metodológico, a elaboração dos EIDHs deve estar fundada na análise de critérios quantitativos (dados demográficos e estatísticos) e qualitativos (entrevistas, questionários) que permitam detectar as violações aos direitos humanos ${ }^{48}$. A execução dos estudos deve estar a cargo, dentro de padrões de efetividade e confiabilidade, de especialistas independentes, como centros de estudos, clínicas, think tanks, e organizações dedicadas à proteção dos direitos humanos, com custos compartilhados entre credores e devedores. Outra opção, como defendida por VILLAROMAN (2015, p.5), é justamente a de que os estudos sejam conduzidos por órgãos de proteção de direitos humanos no próprio país devedor e executor do projeto, desde que comprovada sua competência e autonomia em relação ao Estado/parte tomadora do empréstimo internacional.

Outros critérios informando a execução dos EIDHs envolvem transparência, pertinência e normatividade. Quanto à transparência, processos de análise dos EIDHs devem oferecer subsídios para informação pública, contestabilidade e atuação colaborativa, particularmente de organizações não governamentais, setores da sociedade civil, academia e governos. Sob o critério da pertinência, entende-se que os estudos devam refletir a realidade local do governo-alvo do projeto, com indicadores consistentes de programas e ações de políticas

48 HARRISON (2011) critica exaustivamente a metodologia para os EIDHs, sustentando que a razão principal das falhas existentes decorre muito mais da pouca utilização pelas organizações. $O$ autor sugere que algumas estratégias podem levar ao incremento do conhecimento coletivo sobre aspectos metodológicos fundamentais dos processos de EIDHs, tais como o apoio mais contundente e orientação para essas avaliações, aplicando-se também para a esfera empresarial; e o acompanhamento dos estudos com o objetivo de sinalizar e divulgar boas e más práticas pelas partes envolvidas nos projetos. 
públicas em matéria de direitos humanos ${ }^{49}$. Por fim, a normatividade refere-se à conexão, material e formal, dos EIDHs com o quadro normativo das obrigações internacionais de proteção dos direitos humanos.

Os relatórios finais de avaliação devem apontar claramente as conclusões sobre os efeitos dos projetos sobre padrões de observância de direitos humanos, a exemplo do que ocorre, resguardadas as devidas proporções, nos estudos de impactos ambientais: (i) inexistência de impactos negativos; (ii) lista de potenciais violações de direitos humanos e reajustamento das condicionantes do acordo de empréstimo; (iii) 'trade-off' ou contrabalanceamento entre violações de alguns direitos pela execução do projeto e o cenário de violação de outros direitos, caso ele não se implemente; (iv) identificação das violações de direitos humanos e, dada a seriedade, a recomendação pela resilição ou suspensão da execução do contrato de empréstimo até que as correções ou alterações materiais sejam aplicadas pelo estado receptor/beneficiário e pelo credor/outorgante do empréstimo.

Em suma, a aplicação de salvaguardas socioambientais pode ser reforçada pela adoção dos EIDHs no processo de negociação e conclusão das operações de financiamento internacional de projetos governamentais. Os EIDHs resultam, no limite, na formulação e adoção de indicadores e padrões normativos transnacionais, que podem espelhar, de modo mais adequado, a interação entre as obrigações bilaterais e multilaterais financeiras e obrigações de proteção dos direitos humanos e do meio ambiente.

\section{Conclusões}

O presente artigo buscou examinar o percurso gradual, no direito internacional, do reconhecimento de fragilidades no regime de responsabilidade de estados e organizações internacionais em operações de financiamento de projetos governamentais, tendo como contraponto a reclamada observância de salvaguardas socioambientais. Como sustentado, parecem existir assimetrias entre o quadro de elaboração e cumprimento de salvaguardas

49 Esse aspecto reflete-se na percepção de que direitos humanos podem ser mensurados, em princípio, pela prática e resultados de políticas públicas adotadas pelo Estado, como sugere LANDMAN (2004, p. 926 e ss). A mensuração incluiria a codificação normativa, análise baseada em eventos, padrões e sistemáticas de proteção dos DHs, além de evidências fundadas em questionários, e indicadores agregados que servem como medidas indiretas de proteção de direitos. 
socioambientais nos acordos, como as adotadas pelo Banco Mundial, em projetos com estados receptores/tomadores de financiamento, e a própria compreensão sobre o alcance e a imperatividade das normas de proteção dos direitos humanos e do meio ambiente na ordem jurídica internacional.

Esse tema, portanto, merece tratamento mais engajado e socialmente responsável por parte das organizações e estados. Do ponto de vista dos projetos e linhas de financiamento de bancos de fomento e agências financeiras multilaterais, por exemplo, deve haver maior convergência das salvaguardas socioambientais propostas com as obrigações multilaterais vigentes de proteção dos direitos humanos e meio ambiente - sintetizdas, por exemplo, nas obrigações de respeitar, cumprir e proteger direitos e garantias das populações locais afetadas, assim como as de respeito às normas de jus cogens. Não se trata apenas, a nosso ver, de obrigações interestatais ou relegadas aos mandatos das Nações Unidas e sistemas regionais.

Da mesma forma, as salvaguardas socioambientais, a serem interpretadas sempre de modo consistente com os tratados de direitos humanos e do meio ambiente, não poderiam ser pretexto para legitimar maior endividamento por parte dos Estados receptores. As funções desempenhadas pelo perito especializado das Nações Unidas (ao concentrar missões de investigação e de análise em Membros que sejam tomadores de empréstimos para financiamento de projetos governamentais), poderiam serviriam, nesse sentido, como funções dissuasoras da continuidade de condutas eventualmente lesivas às comunidades afetadas. Como visto, é papel do Perito Especial, igualmente, verificar a viabilidade das medidas adotadas pelos governos, setor privado e as instituições financeiras internacionais para mitigar os resultados potencialmente prejudiciais dos financiamentos sobre países em desenvolvimento, especialmente os países mais pobres e aqueles altamente endividados.

O tratamento do tema ora examinado também exige a formulação de um princípio de máxima observância das normas internacionais e domésticas de direitos humanos (como em tratados e constituições) na formulação, negociação e execução dos acordos de empréstimos entre estados e organizações financeiras e agências de fomento internacionais. Nesse sentido, reforça-se a aplicação dos Princípios Diretrizes sobre Dívida Externa e Direitos Humanos de 2012, sobretudo por seu objetivo sistêmico de preservação do equilíbrio entre obrigações contratuais do Estado devedor e credor e obrigações relativas aos direitos humanos, sobretudo os direitos econômicos, sociais e culturais. 
A convergência entre salvaguardas socioambientais e obrigações multilaterais de proteção dos direitos humanos e meio ambiente também abre espaço, como visto, para a concepção de uma nova e justa governança das organizações internacionais. Essa abordagem somente parece se justificar se houver mecanismos efetivos de construção de um neofederalismo das organizações financeiras internacionais e as Nações Unidas na formulação de princípios de justa governança (fair governance). A governança das organizações não apenas diz respeito a um regime de estruturas e funcionamento, mas antes de responsabilidades, de transparência e de controle externo.

Quanto às lições trazidas pela prática brasileira, ilustrada anteriormente pelos casos Planaforo, Itaparica e Biodiversidade Paraná, algumas conclusões podem ser apontadas. Além da manifesta assimetria envolvendo os graus de responsabilidade internacional do Estado e do Banco Mundial no financiamento de projetos governamentais com impactos socioambientais, observa-se a fragilidade de órgãos de monitoramento, como o Painel de Inspeção. Os casos demonstram duplamente as inconsistências de procedimentos de investigação e inefetividade do acompanhamento dos projetos financiados, e a exposição das comunidades locais e grupos vulneráveis, a danos socioambientais.

São danos que potencialmente se qualificam como resultado de atos ilícitos praticados pelos Estados (em seus entes federativos), em concorrência com conduta omissiva da organização - o Banco Mundial- e que repercutem na esfera dos direitos humanos das populações afetadas e do direito ao meio ambiente ecologicamente equilibrado. Degradação ambiental, destruição de bens do patrimônio histórico e cultural, deslocamento forçado em zonas de grandes construções (e.g. barragens, reservatórios e hidrelétricas), além da violência e empobrecimento generalizados, são apenas alguns dos resultados prejudiciais decorrentes da má execução dos projetos governamentais financiados.

Por fim, experiências relatadas no repertório de projetos governamentais financiados por organismos, bancos de desenvolvimento e agências de fomento internacionais nas últimas décadas demonstram a seriedade das preocupações da sociedade civil internacional, academia e especialistas em políticas públicas. Elas parecem oferecer fundamentos empíricos para revisão de princípios e regras de direito internacional em matéria de responsabilidade socioambiental dos estados e organizações internacionais. Ainda que se reconheça o deficit do regime das responsabilidades, no atual estágio de evolução dos instrumentos e procedimentos de direito 
internacional existentes (tratados, princípios, mecanismos de solução de controvérsias, limites jurisdicionais de órgãos e tribunais), é possível sustentar a necessidade de adensamento das bases normativas conducentes para um compartilhamento de responsabilidades entre estados e organizações internacionais. A razoável solidariedade, nesse domínio, refere-se aos atos de concepção, monitoramento, execução e implementação dos projetos financiados, com a adoção de medidas preventivas e repressivas. Essas medidas, como observado, são reforçadas pela disseminação de Estudos de Impactos de Direitos Humanos resultantes dos projetos, especialmente porque enfatizam a aplicação de indicadores e padrões normativos globalmente admitidos na área de intersecção entre direito internacional econômico e o direito internacional dos direitos humanos.

Belo Horizonte/Rio de Janeiro/Americana, Dezembro de 2016.

\section{Bibliografia}

ABOUHARB, M. Rodwan; CINGRANELLI, David L. "The human rights effects of World Bank structural adjustment”, 1981-2000. International Studies Quarterly, v. 50, n. 2, 2006, p. 233-262.

BARNETT, Michael N., e FINNEMORE, Martha. "The Politics, Power, and Pathologies of International Organizations”. International Organization vol. 53, p. 699-732, 1999.

BISSELL, Richard E. "Recent practice of the inspection panel of the World Bank".American Journal of International Law, p. 741-744, 1997.

BRADLOW, Daniel D. "International Organizations and Private Complaints: The Case of the World Bank Inspection Panel." Virginia Journal of International Law, v. 34, 1993, p. 553-613

BRADLOW, Daniel. "The World Bank, the IMF, and human rights", in Journal of Transnational Law and Contemporary Problems, vol. 6, 1996, p.47-90.

BUNTAINE, Mark T. "Accountability in Global Governance: Civil Society Claims for Environmental Performance at the World Bank." International Studies Quarterly, v. 59, n. 1, 2015, p. 99-111.

CERENA, Michael M. "Involuntary resettlement in development projects", in World Bank Technical Paper, n. 80, 1998, p. 373-384.

CERNEA, Michael M. "Risks, safeguards and reconstruction: a model for population displacement and resettlement." Economic and Political Weekly, 2000, p. 3659-3678.

CIORCIARI, John D. "Lawful Scope of Human Rights Criteria in World Bank Credit Decisions: An Interpretive Analysis of the IBRD and IDA Articles of Agreement", in Cornell International Law Journal, vol. 33, 2000, p.331-47. 
CLARK, Dana L. "World Bank and Human Rights: The Need for Greater Accountability", in Harvard Human Right Journal, vol.15, 2002, p.205-28.

CLARK, Dana; FOX, Jonathan A.; TREAKLE, Kay (Ed.). Demanding Accountability: Civil Society Claims and the World Bank Inspection Panel. Rowman \& Littlefield Publishers, 2003.

DAHL, Robert A. Can International Organizations Be Democratic?, in Ian SHAPIRO e Casiano Hacker-Cordón (eds.) A Skeptic's View. In Democracy's Edges, Cambridge: Cambridge University Press, 1999, pp. 19-36.

FOX, Jonathan. "The uncertain relationship between transparency and accountability." Development in Practice, v. 17, n. 4-5, p. 663-671, 2007.

GOLDMAN, Sacha. O mundo não tem mais tempo a perder. Rio de Janeiro: Civilização Brasileira, 2014.

HARRISON, James. "Human rights measurement: reflections on the current practice and future potential of human rights impact assessment", in Journal of Human Rights Practice vol.3, n.2, 2011, p.162-187.

HERBERTSON, Kirk. "Will Safeguards Survive the Next Generation of Development Finance?". International Rivers, 2012.

HEY, Ellen. "The World Bank Inspection Panel and the Development of International Law." In: International Courts and the Development of International Law. TMC Asser Press, 2013, p. 727-738.

HUNTER, David. "Using the World Bank Inspection Panel to Defend the Interests of Projectaffected People." Chicago Journal of International Law, v. 4, 2003, p. 201.

HUPPMAN, L. Reed. "Implementing International Good Practice Standards: Pragmatism Versus Philosophy.” In: Responsible Investment Banking. Springer International, 2015, p. 333-338.

KAPUR, Devesh. The changing anatomy of governance of the World Bank in: PINCUS, Jonathan; WINTERS, Jeffrey Alan. Reinventing the World Bank. Ithaca: Cornell University Press, 2002, p.54-75.

KINLEY, David; TADAKI, Junko. "From talk to walk: The emergence of human rights responsibilities for corporations at international law." Virginia Journal of International Law, v. 44, n. 4, 2004, p. 931-1023.

LANDMAN, Todd. "Measuring human rights: principle, practice and policy", in Human Rights Quarterly, vol. 26, n. 4, 2004, p. 906-931

LEVINSON, Jerome. "Multilateral Financing Institutions: What Form of Accountability." American University Journal of International Law \& Policy, v. 8, 1992, p. 3963

MARSCHINSKI, Robert; e BEHRLE, Steffen. "The World Bank: Making the business case for the environment", in Frank BIERMANN e Bernd SIEBENHÜNER (ed), Managers of Global Change: The Influence of International Environmental Bureaucracies. MIT Press: Cambridge/MA, 2009. p.103-141. 
MEYERSTEIN, Ariel. Transnational Private Financial Regulation and Sustainable Development: An Empirical Assessment of the Implementation of the Equator Principles. New York University Journal of Internatinal Law \& Policy., v. 45, 2012, p. 487-99.

NINIO, Alberto. "Organizações Internacionais e Responsabilidade: O caso do painel de inspeção do Banco Mundial", in RDE-Revista de Desenvolvimento Econômico, v. 3, n. 5, 2009, p.61-67.

NYE, Joseph S. "Globalization's Democratic Deficit: How to Make International Institutions More Accountable". Foreign Affairs, vol.80, 2001, pp. 2-6.

RICH, Bruce. Mortgaging the earth: The World Bank, environmental impoverishment, and the crisis of development. Washington, D.C: Island Press, 2013.

RICH, Bruce. World Bank Group's flight from sustainability. Draft Paper. 2015, p.1-38 (mímeo com autor).

SHIHATA, Ibrahim FI. "Human Rights, Development, and International Financial Institutions." American University Journal of International Law \& Policy, v. 8, 1992, p. 27-37.

STEPHANOU, Michelle C. Análise comparativa das metodologias de avaliação das agências de fomento internacionais BID e BIRD em financiamentos de projetos sociais no Brasil. CivitasRevista de Ciências Sociais, v. 5, n. 1, 2006.

TOMASEVSKI, Katarina. "Monitoring Human Rights Aspects of Sustainable Development." American University International Law Review 8, no. 1, 1992, p.77-102.

VILLAROMAN, Noel. Loan Agreements and Human Rights: The Role of Human Rights Impact Assessments, in Regional Consultation on the Draft Guidelines on Foreign Debt and Human Rights. UN Office of the High Commissioner for Human Rights. 2011.

VIÑUALES, Jorge E. Foreign investment and the environment in international law. Cambridge University Press, 2012.

WINTERS, Matthew S. Liam Clegg. 2013. "Controlling the World Bank and IMF: Shareholders, stakeholders, and the politics of concessional lending (New York: Palgrave Macmillan)." The Review of International Organizations, v. 9, n. 1, 2014, p. 131-134.

WOODS, Ngaire; NARLIKAR, Amrita. "Governance and the Limits of Accountability: The WTO, the IMF, and the World Bank." International Social Science Journal, v. 53, n. 170, 2001, p. 569-583.

WRIGHT, Christopher. "Global banks, the environment, and human rights: The impact of the Equator Principles on lending policies and practices." Global Environmental Politics, v. 12, n. 1, 2012, p. 56-77.

ZALCBERG, Jacqui. World Bank Inspection Panel: A Tool for Ensuring the World Bank's Compliance with International Law, Macquarie Journal of International Lawe \& Comparative. Environmetnal. Law, v. 8, p. 75, 2012.

ZHOU, Suzanne. Reassessing the prospects of a human rights safeguard policy at the World Bank, in Journal of International Economic Law, Vol.15, n.3, 2012, p.823-841. 
WOODS, Ngaire. Good governance in international organizations, in: Global Governance, vol. 5, n. 1, 1999, p. 39-61.

DIEHL, Paul Francis; FREDERKING, Brian (Ed.). The politics of global governance: international organizations in an interdependent world. Boulder, CO: Lynne Rienner Publishers, 1997.

STIGLITZ, Joseph E. Democratizing the International Monetary Fund and the World Bank: governance and accountability. Governance, v. 16, n. 1, 2003, p. 111-139.

\section{Documentos}

AGU, Manual de Financiamentos Externos - Setor Público. Brasília: Advocacia Geral da União. 2013.

BANCO MUNDIAL, Brazil - Itaparica Resettlement and Irrigation Project : Management Response to the Request for Inspection, Washington/DC: World Bank. 1997. Disponível em: $<\mathrm{http}: / /$ documents.worldbank.org/curated/en/242831468744265638/pdf/28463.pdf $>$.

BANCO MUNDIAL, Brazil - Memorandum to the executive directors and alternates of the international development association. Washington/DC: World Bank. 2006. Disponível em: < http://documents.worldbank.org/curated/en/179901468238745959/pdf/367730rev0pdf.pdf >.

BANCO MUNDIAL, Brazil - Itaparica Resettlement and Irrigation Project : Request for Inspection. Washington/DC: World Bank. 1997.

BANCO MUNDIAL, Brazil - Land Reform and Poverty Alleviation Pilot Project: Report and Recommendation on the Request for Inspection. Washington/DC: World Bank. 1999. Disponível em: <http://documents.worldbank.org/curated/en/1999/05/3665693/brazil-land-reform-povertyalleviation-pilot-project-request-1-report-recommendation-request-inspection $>$.

BANCO MUNDIAL, Brazil - Parana Biodiversity Project. Washington/DC: World Bank. 2002. Disponível

em:

$<$ http://documents.worldbank.org/curated/en/895231468770371978/pdf/multi0page.pdf >.

BANCO MUNDIAL, Operational Manual Statement on Environmental Aspects of World Bank Work, 1984.

BANCO MUNDIAL, Review and update of the World Bank' safeguard policies proposed environmental and social framework. Background Paper. September 2, 2014, p.9 Disponível em: $\quad<$ https://consultations.worldbank.org/consultation/review-and-update-world-banksafeguard-policies >. Acesso em 20 de dezembro de 2016. 
BID, Política de Constituição do Mecanismo Independente de Consulta e Investigação do Banco Interamericano de Desenvolvimento. Fevereiro de 2010. Disponível em $<$ http://idbdocs.iadb.org/wsdocs/getdocument.aspx?docnum=36450883 $>$. Acesso em 20 de dezembro de 2016.

BID, Política de Medio Ambiente y Cumplimiento de Salvaguardias. 19 de enero, 2006. Disponível em: $<$ http://idbdocs.iadb.org/wsdocs/getdocument.aspx?docnum=39430551 $>$. Acesso em 20 de dezembro de 2016.

HUMAN RIGHTS COUNCIL, A/HRC/28/59/Add.1 Report of the Independent Expert on the effects of foreign debt and other related international financial obligations of States on the full enjoyment of all human rights, particularly economic, social and cultural rights, Juan Pablo Bohoslavsky. Disponível em: $\quad<\quad$ https://documents-ddsny.un.org/doc/UNDOC/GEN/G15/059/79/PDF/G1505979.pdf?OpenElement>.

ONU, Convenção sobre Privilégios e Imunidades das Agências Especializadas das Nações Unidas, de 21 de novembro de 1947.

ONU, Resolução 11/5 do Conselho de Direitos Humanos, de 17 de junho de 2009.

SENADO FEDERAL, Empréstimos internacionais feitos por estados e municípios brasileiros e o problema do crédito externo ser atrelado ao dólar, in Em Discussão: Revista de Audiências Públicas do Senado, vol.4, 2013.

UN Human Rights Council, A/HRC/28/L.14, The effects of foreign debt and other related international financial obligations of States on the full enjoyment of all human rights, particularly economic, social and cultural rights. 23 March 2015. Disponível: $<$ http://www.ohchr.org/EN/Issues/Development/IEDebt/Pages/AnnualReports.aspx $>$ UN Human Rights Council. A/HRC/28/59. Report of the Independent Expert on the effects of foreign debt and other related international financial obligations of States on the full enjoyment of human rights, particularly economic, social and cultural rights, Juan Bohoslavsky - Report on financial complicity: lending to States engaged in gross human rights violation. Disponível: $<$ http://www.ohchr.org/EN/Issues/Development/IEDebt/Pages/AnnualReports.aspx $>$ 
UN Human Rights Council. A/HRC/28/60. Illicit financial flows, human rights and the post2015 development agenda, Interim study by the Independent Expert on the effects of foreign debt and other related international financial obligations of States on the full enjoyment of all human rights, particularly economic, social and cultural rights, Juan Pablo Bohoslavsky. Disponível: $<$ http://www.ohchr.org/EN/Issues/Development/IEDebt/Pages/AnnualReports.aspx $>$ 